\title{
Duration of Implantable Cardiac Monitoring and Detection of Atrial Fibrillation in Ischemic Stroke Patients: A Systematic Review and Meta-Analysis
}

\author{
Georgios Tsivgoulis, ${ }^{\mathrm{a}, \mathrm{b}}$ Aristeidis H. Katsanos, ${ }^{\mathrm{a}, \mathrm{c}}$ Martin Köhrmann, ${ }^{\mathrm{d}}$ Valeria Caso, ${ }^{\mathrm{e}}$ Fabienne Perren, ${ }^{\mathrm{f}}$ \\ Lina Palaiodimou, ${ }^{\text {a }}$ Spyridon Deftereos, ${ }^{\mathrm{g}}$ Sotirios Giannopoulos, ${ }^{\mathrm{c}}$ John Ellul, ${ }^{\mathrm{h}}$ Christos Krogias, ${ }^{\mathrm{i}}$ \\ Dimitris Mavridis, ${ }^{\mathrm{j}}$ Sokratis Triantafyllou, ${ }^{\mathrm{a}}$ Anne W. Alexandrov, ${ }^{\mathrm{b}}$ Peter D. Schellinger, ${ }^{\mathrm{k}}$ \\ Andrei V. Alexandrov ${ }^{b}$

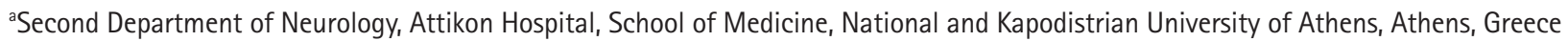 \\ 'Department of Neurology, University of Tennessee Health Science Center, Memphis, TN, USA \\ 'Department of Neurology, University of loannina School of Medicine, Ioannina, Greece \\ ${ }^{\mathrm{d} D e p a r t m e n t}$ of Neurology, Essen University Hospital, Essen, Germany \\ 'Stroke Unit, Division of Cardiovascular Medicine, University of Perugia, Perugia, Italy \\ fDepartment of Neurology, University Hospital of Geneva, Geneva, Switzerland \\ ${ }^{9}$ Second Department of Cardiology, Attikon Hospital, School of Medicine, National and Kapodistrian University of Athens, Athens, Greece

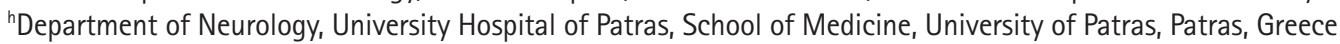 \\ 'Department of Neurology, St. Josef-Hospital, Ruhr University, Bochum, Germany \\ 'Department of Primary Education, University of loannina, loannina, Greece \\ kDepartment of Neurology and Neurogeriatry, Johannes Wesling Medical Center, Ruhr University Bochum, Minden, Germany
}

Background and Purpose Current guidelines do not provide firm directions on atrial fibrillation (AF) screening after ischemic stroke (IS). We sought to investigate the association of implantable cardiac monitoring (ICM) duration with the yield of AF detection in IS patients.

Methods We included studies reporting AF detection rates by ICM in IS patients with negative initial AF screening. We excluded studies reporting prolonged cardiac monitoring with devices other than ICM, not providing AF detection rates or monitoring duration, and reporting overlapping data for the same population. The random-effects model was used for all pooled estimates and meta-regression analyses.

Results We included 28 studies (4,531 patients, mean age 65 years). In meta-regression analyses, the proportion of AF detection by ICM was independently associated with monitoring duration (coefficient $=0.015 ; 95 \%$ confidence interval $[\mathrm{Cl}], 0.005$ to 0.024 ) and mean patient age (coefficient=0.009; $95 \% \mathrm{Cl}, 0.003$ to 0.015 ). No associations were detected with other patient characteristics, including IS subtype (cryptogenic vs. embolic stroke of undetermined source) or time from IS onset to CM implantation. In subgroup analyses, significant differences $(P<0.001)$ in the AF detection rates were found for ICM duration ( $<6$ months: $5 \%$ [95\% Cl, 3\% to $6 \%$; $; \geq 6$ and $\leq 12$ months: $21 \%$ [95\% Cl, 16\% to 25\%]; >12 and $\leq 24$ months: $26 \%$ [95\% Cl, 22\% to $31 \%$ ]; > 24 months: $34 \%$ [95\% Cl, 29\% to $39 \%]$ ).

Conclusions Extended duration of ICM monitoring and increased patient age are factors that substantially increase AF detection in IS patients with initial negative AF screening.
Correspondence: Georgios Tsivgoulis Second Department of Neurology, Attikon Hospital, School of Medicine, National and Kapodistrian University of Athens, Iras 39, Gerakas Attikis, Athens 15344, Greece Tel: +30-6937178635

Fax: +30-2105832471 E-mail: tsivgoulisgiorg@yahoo.gr

Received: May 5, 2019

Revised: June 4, 2019

Accepted: June 14, 2019 


\section{Introduction}

Approximately one-third of all ischemic strokes (IS) are characterized as cryptogenic strokes (CS), due to the lack of a possible cause for the event or incomplete diagnostic work-up. ${ }^{1-3}$ Atrial fibrillation (AF), either paroxysmal or chronic, represents a major risk factor for stroke and systemic embolism, and is associated with a 5-fold increase in IS risk. ${ }^{4.5}$ Although paroxysmal AF appears to be implicated in at least $30 \%$ of patients with CS and in approximately $25 \%$ of patients with unselected $I_{1},{ }_{1}^{6,7}$ current guidelines on secondary stroke prevention do not provide firm directions on AF screening after IS.

The American Heart Association/American Stroke Association (AHA/ASA) recommendations on secondary stroke prevention suggest that prolonged rhythm monitoring for approximately 30 days is reasonable for AF screening within 6 months after CS (Class Ila; Level of Evidence C), ${ }_{1}^{8}$ while the recent AHA/ASA guidelines on the early management of IS patients indicate that the clinical benefit of prolonged cardiac monitoring to detect $\mathrm{AF}$ remains uncertain (Class of Recommendation: Ilb, Level of Evidence: B). ${ }^{9}$ However, clinical trials ${ }^{6,10}$ suggest that implantable cardiac monitors (ICMs) substantially increase AF detection in IS patients, due to prolonged monitoring duration.

In the present systematic review and meta-analysis, we sought to investigate the association of ICM duration with the level of AF detection in IS patients. We also assessed whether IS subtype, patient characteristics, and elapsed time between IS onset and CM implantation may affect the probability of AF detection.

\section{Methods}

\section{Search strategy and selection criteria}

This study was conducted according to the Preferred Reporting Items of Systematic Reviews and Meta-Analyses (PRISMA) statement. ${ }^{11}$ We searched for studies reporting AF detection rates by ICM in patients with history of IS or transient ischemic attack (TIA). A literature search in MEDLINE, SCOPUS, and the Cochrane Central Register of Controlled Trials (CENTRAL) was performed, using the following terms in combination: "cardiac monitoring," "implantable loop recorder," "insertable loop recorder," "implantable cardiac monitor," "cryptogenic stroke," "embolic stroke of undetermined source," "ischemic stroke," "cerebral ischemia," "atrial fibrillation," and "atrial flutter." The complete algorithm used in the MEDLINE database search is available in the online Supplementary Methods. Eligible studies were also sourced from a manual search of key journals, conference proceedings and other (non-Cochrane) systematic reviews and meta-analyses. No language or other search restrictions were applied. The last literature search was performed on July 10, 2018.

We included all studies (randomized clinical trials [RCTs], prospective/retrospective cohort studies, case-control studies) reporting detection rates of AF by ICM in patients with history of IS or TIA. We excluded from further evaluation all case reports, case series, studies reporting cardiac monitoring with devices other than ICM, and studies not providing AF detection rate or monitoring duration with ICM. We also excluded studies reporting overlapping population data, and included only the study with the highest number of patients and/or more extended follow-up time. However, we retained publications providing data for distinct IS groups, including CS and embolic stroke of undetermined source (ESUS), despite the possibility of overlapping group data (ESUS overlapping with CS, and CS/ESUS overlapping with unselected IS/TIA). Reference lists of all articles that met the inclusion criteria, and of relevant review articles, were examined to identify studies that may have been missed by the initial database search. All retrieved studies were scanned independently by two reviewers (G.T. and A.H.K.). In case of disagreement regarding the literature search results between the two coauthors, the remaining coauthors were consulted, and disagreement was ultimately resolved with consensus. We used the Newcastle-Ottawa Scale to assess the quality of included studies that were published at the time of the literature search, and to identify potential sources of bias amongst eligible studies. ${ }^{12}$ Quality control and bias identification were performed independently by the same authors who performed the literature search (G.T. and A.H.K.), and all potential disagreements were resolved after discussion and mutual consensus.

The minimum required AF duration, for diagnosing AF with ICM, was documented separately for each study protocol. We calculated the ICM AF detection rates for different ICM durations by dividing the number of events (patients with detected AF) by the total number of patients receiving ICM. After the overall analysis we performed meta-regression analyses for all study and patient characteristics that were available in 10 or more of the included studies. ${ }^{13}$ We also conducted pre-defined subgroup analyses according to the study type (prospective or retrospective cohort), study population (CS, ESUS, unselected IS/TIA), the specific time threshold used for AF diagnosis (30 seconds, 2 minutes, 6 minutes), the monitoring duration $(<6$, $\geq 6$ and $\leq 12$, $>12$ and $\leq 24$, $>24$ months), the ICM device used, and the elapsed time between IS/TIA onset and implantation of $\mathrm{CM}$ ( $\leq 1$ and $>1$ month), provided that at least two studies were included in each subgroup. Finally, for all the aforementioned meta-regression and subgroup analyses, we performed additional sensitivity analyses after excluding studies that were 
presented in conferences and had only abstracts publicly available at the time of the literature search. Data extraction was performed by two independent authors (A.H.K. and L.P.), and in cases of disagreement, a senior author (G.T.) was consulted.

For all proportion analyses we used the variance-stabilizing double arcsine transformation. ${ }^{14}$ Pooled estimates in both the overall and subgroup analyses were calculated using the Hartung-Knapp-Sidik-Jonkman method. ${ }^{15}$ Meta-regression analyses were performed under the random-effects model (method of moments). Variables with a threshold of $P<0.1$ in the initial univariate meta-regression analyses were used as covariates for multivariate meta-regression models. Due to the established relationship of age with $\mathrm{AF}$ incidence, ${ }^{16}$ mean age was included as an a priori potential confounder in all multivariate models. The equivalent $z$ test was performed for each pooled estimate and $P<0.05$ was considered statistically significant. We assessed heterogeneity between studies with the Cochran $\mathrm{Q}$ and $\mathrm{I}^{2}$ statistics. ${ }^{17}$ For all subgroup analyses we used a standard test for heterogeneity across subgroup results, to investigate for potential differences between subgroups, as previously described. ${ }^{18}$ Small-study effect (i.e., publication bias) across individual studies was evaluated graphically using both funnel plot inspection and the Egger's linear regression test, at a significance level of 0.1. ${ }^{19}$

All statistical analyses were performed using Stata Statistical Software Release version 13 for Windows (StataCorp LP, College Station, TX, USA) and OpenMeta-Analyst software. ${ }^{20}$

Since the present work is a systematic review and metaanalysis of previously published studies, IRB approval was waived.

\section{Results}

The PRISMA flowchart summarizing the literature search process is shown in Supplementary Figure 1. MEDLINE and SCOPUS literature searches retrieved 375 and 417 results respectively, while comprehensive searches of key journals and conference proceedings identified 20 additional studies. Of all potentially eligible studies, 18 study protocols were excluded (Supplementary Table 1) due to overlapping data $(n=4)$, the use of monitoring devices other than ICM $(n=11)$, or unavailable information on ICM duration $(n=3)$. Our literature search highlighted 28 studies for inclusion, comprising 4,531 patients (mean age 65 years, 52\% male). ${ }^{6,21-48}$ Protocols and patient characteristics of included studies are briefly summarized in Table 1 and Supplementary Table 2, respectively. Most studies were conducted in the USA ( $n=9)$ and Germany $(n=8)$. The most common subgroup studied was cryptogenic IS/TIA ( $n=17)$, followed by ESUS $(n=9)$. The mean/median elapsed time from IS/TIA onset to cardiac monitoring implantation ranged from 3 to 174 days, while the mean/median ICM duration ranged from 180 to 1,080 days (Table 1). Included studies were generally found to have a low risk of bias (Supplementary Table 3), except in cases not clearly stating consecutive enrollment of patients, ${ }^{23,26,27,39,44-47}$ exclusion of AF with electrocardiogram or short-term non-invasive Holter monitoring prior to ICM impantation, ${ }^{21,33}$ or no adjudication of ICM recordings by experienced cardiologists. ${ }^{26-29,33,41,46,47}$

In the overall analysis of all included studies, the cumulative AF detection rate in patients with ICM was 26\% (95\% confidence interval [Cl], 22\% to $30 \%$ ), with significant heterogeneity among studies $\left(I^{2}=83 \%, P\right.$ for Cochran $\left.0<0.001\right)$ (Supplementary Figure 2). No evidence for publication bias was identified by funnel plot inspection (Supplementary Figure 3) or by the Egger's statistical test $(P=0.525)$. In univariate meta-regression analyses of all included studies (Table 2 ) the proportion of AF detection by ICM was positively associated with the duration of monitoring (coefficient $=0.009 ; 95 \% \mathrm{Cl}, 0.005$ to 0.013 ; $P<0.001)$ (Figure $1 \mathrm{~A})$ and mean patient age $(P=0.018)$ (Supplementary Figure 4A). No associations were detected with other patient characteristics (Supplementary Figures 5A and $9 A)$, including sex $(P=0.100)$ (Supplementary Figure $5 A)$, hypertension $(P=0.215)$ (Supplementary Figure $6 A)$, diabetes mellitus $(P=0.140)$ (Supplementary Figure $7 \mathrm{~A})$, mean patient $\mathrm{CHA}_{2} \mathrm{DS}_{2}-$ VASc score $(P=0.232)$ (Supplementary Figure $8 A)$, or elapsed time from IS/TIA onset to cardiac monitor implantation $(P=0.363)$ (Supplementary Figure $9 A)$. In multivariate analyses, both monitoring duration (coefficient $=0.015 ; 95 \% \mathrm{Cl}, 0.005$ to 0.024; $P=0.003$ ) and mean patient age (coefficient $=0.009$; $95 \% \mathrm{Cl}, 0.003$ to $0.015 ; P=0.004)$ were independently associated with the proportion of AF detection (Table 2).

In the sensitivity univariate meta-regression analyses of published studies (Supplementary Table 4) duration of ICM (coefficient $=0.007 ; 95 \% \mathrm{Cl}, 0.001$ to $0.014 ; P=0.049)$ (Figure 1B), history of hypertension (coefficient $=0.005 ; 95 \% \mathrm{Cl}, 0.001$ to $0.010 ; P=0.029$ ) (Supplementary Figure $6 \mathrm{~B}$ ), and diabetes mellitus (coefficient $=0.013 ; 95 \% \mathrm{Cl}, 0.001$ to $0.024 ; P=0.033$ ) (Supplementary Figure $7 \mathrm{~B}$ ) were positively associated with higher rates of AF detection, while no association was detected with other patient characteristics (Supplementary Figures $4 B$, $5 B, 8 B$, and $9 B$ ). However, in multivariate analyses only monitoring duration (coefficient $=0.009 ; 95 \% \mathrm{Cl}, 0.003$ to 0.015 ; $P=0.006$ ) and mean patient age (coefficient $=0.037 ; 95 \% \mathrm{Cl}$, 0.013 to 0.062 ; $P=0.007$ ) were independently associated with the proportion of AF detection (Supplementary Table 4).

In subgroup analyses of all included studies (Table 3), there 
Table 1. Characteristics of included studies

\begin{tabular}{|c|c|c|c|c|c|c|c|c|}
\hline Study & Country & $\begin{array}{l}\text { No. of } \\
\text { patients }\end{array}$ & Population & Device & $\begin{array}{l}\text { Monitoring time } \\
\text { (day) }\end{array}$ & $\begin{array}{l}\text { Implantation after } \\
\text { event (day) }\end{array}$ & $\begin{array}{l}\text { Insertion to AF } \\
\text { detection (day) }\end{array}$ & $\begin{array}{c}\text { AF } \\
\text { definition }\end{array}$ \\
\hline Asaithambi et al. $(2017)^{21 *}$ & USA & 114 & $\mathrm{CS}$ & NR & $415(268-557)$ & NA & $53(5-132)$ & NA \\
\hline Carrazco et al. $(2018)^{22}$ & USA & 100 & CS & $\begin{array}{c}\text { Reveal XT/ } \\
\text { Reveal } \\
\text { LINO }\end{array}$ & $240-540$ & $4.2 \pm 2.6$ & 34 & $>2 \min$ \\
\hline Ching et al. $(2018)^{23 *}$ & USA & 177 & ESUS & Reveal LINO & $478 \pm 179$ & NA & NA & NA \\
\hline Cotter et al. $(2013)^{24}$ & UK & 51 & CS & Reveal XT & $229 \pm 116$ & $174 \pm 134$ & 48 & $>2 \min$ \\
\hline CRYSTAL-AF (2014) ${ }^{6}$ & Multicenter & 221 & $\mathrm{CS}$ & Reveal XT & 1,080 & $38.1 \pm 27.6$ & $41(14-84)$ & $>30 \mathrm{sec}$ \\
\hline CRYSTAL-AF $(2017)^{25 *}$ & Multicenter & 122 & ESUS & Reveal XT & NA & NA & NA & $\geq 2 \min$ \\
\hline de Lera et al. (2016) $)^{26 *}$ & Spain & 163 & ESUS & NR & $616 \pm 340$ & NA & NA & $>2 \mathrm{~min}$ \\
\hline Dion et al. $(2010)^{27}$ & France & 24 & $\mathrm{CS}$ & $\begin{array}{c}\text { Reveal Plus } \\
\text { ILR } 9526\end{array}$ & 435 & $90 \pm 30.3$ & NA & $>30 \mathrm{sec}$ \\
\hline Etgen et al. $(2013)^{28}$ & Germany & 22 & $\mathrm{CS}$ & Reveal XT & 360 & $8.5(6.5-10.5)$ & $\begin{array}{c}152.8 \\
(61.6-244.1)\end{array}$ & $>6$ min \\
\hline Israel et al. $(2017)^{29}$ & Germany & 123 & ESUS & Reveal XT & $381 \pm 165$ & 20 & 108 & $>2 \min$ \\
\hline Jorfida et al. $(2016)^{30}$ & Italy & 54 & $\mathrm{CS}$ & Reveal XT & $435(261-675)$ & $108 \pm 60$ & $162(30-540)$ & $>5 \min$ \\
\hline Kamel et al. (2018) $)^{31 *}$ & USA & 886 & Unselected & NR & 720 & NA & NA & NA \\
\hline Katz et al. $(2017)^{32 *}$ & USA & 45 & Unselected & Reveal LINQ & 264 & 10 & 162.7 & NA \\
\hline Kotlarz-Böttcher et al. (2018) & Germany & 100 & ESUS & Reveal LINQ & 362 & NA & NA & NA \\
\hline Makimoto et al. $(2017)^{34}$ & Germany & 146 & ESUS & NR & $387(283-552)$ & NA & NA & $>30 \mathrm{sec}$ \\
\hline Navarro Pérez et al. $(2018)^{35 *}$ & Spain & 37 & CS & NR & 337.95 & 226.6 & 82.5 & NA \\
\hline Noone et al. $(2016)^{36 *}$ & Ireland & 31 & ESUS & NR & 540 & NA & 90 & $>30 \mathrm{sec}$ \\
\hline Pallesen et al. $(2017)^{37 *}$ & Germany & 75 & ESUS & Reveal LINO & NA & NA & 57 & NA \\
\hline Poli et al. $(2016)^{38}$ & Germany & 74 & CS & $\begin{array}{c}\text { Reveal XT/ } \\
\text { Reveal } \\
\text { LINO }\end{array}$ & $311 \pm 251$ & $27 \pm 24$ & $105 \pm 135$ & $>2 \min$ \\
\hline REVEAL-AF $(2018)^{39 *}$ & Multicenter & 79 & Unselected & $\begin{array}{c}\text { Reveal XT/ } \\
\text { Reveal } \\
\text { LINO }\end{array}$ & $540-900$ & - & - & $>6$ min \\
\hline Ritter et al. $(2013)^{40}$ & Germany & 60 & $\mathrm{CS}$ & Reveal XT & $382(89-670)$ & $13(10-67)$ & 64 & $>30 \mathrm{sec}$ \\
\hline Rodríguez-Campello et al. $(2015)^{41 *}$ & Spain & 28 & ESUS & NR & $180(60-360)$ & $5-7$ & $12(10-21)$ & NA \\
\hline Rojo-Martinez et al. $(2013)^{42}$ & Spain & 101 & CS & Reveal XT & $281 \pm 212$ & $<30$ & 102 & $>2 \min$ \\
\hline Sethi et al. $(2017)^{43 *}$ & USA & 197 & $\mathrm{CS}$ & NR & 454 (50-951) & 3 & NA & NA \\
\hline SPIDER Registry $(2015)^{44 *}$ & USA & 64 & CS & $\begin{array}{c}\text { Reveal XT/ } \\
\text { Reveal } \\
\text { LINO }\end{array}$ & 223 & NA & 35 & $>10 \mathrm{sec}$ \\
\hline SURPRISE $(2014)^{45}$ & Denmark & 85 & $\mathrm{CS}$ & Reveal XT & $569 \pm 310$ & $107 \pm 117$ & $109 \pm 48$ & $>2 \min$ \\
\hline TRACK-AF $(2018)^{46}$ & Germany & 105 & CS & Reveal XT & 217 (72.5-338) & $0-28$ & NA & $>30 \mathrm{sec}$ \\
\hline Ziegler et al. $(2015)^{47},(2017)^{48}$ & USA & 1,247 & $\mathrm{CS}$ & Reveal LINQ & $579 \pm 222$ & NA & 112 (35-293) & $>2 \mathrm{~min}$ \\
\hline
\end{tabular}

Values are presented as median (interquartile range), range, or mean \pm standard deviation.

$A F$, atrial fibrillation; CS, cryptogenic stroke; NA, not available; ESUS, embolic stroke of undetermined source; CRYSTAL-AF, Cryptogenic Stroke and underlying Atrial Fibrillation; REVEAL AF, Incidence of AF in High Risk Patients; SPIDER Registry, Stroke Prevention through the Improved Detection of AF registry; SURPRISE, Stroke Prior to Diagnosis of Atrial Fibrillation Using Long-term Observation with Implantable Cardiac Monitoring Apparatus Reveal; TRACK-AF, Followup of Kryptogenic Stroke Patients With Implantable vs. Non-invasive Devices to Detect Atrial Fibrillation.

${ }^{*}$ Conference proceedings abstracts.

were significant differences ( $P$ for subgroup differences $<0.001$ ) in the rates of AF detection in subgroups stratified by ICM duration ( $<6$ months: $5 \%[95 \% \mathrm{Cl}, 3 \%$ to $6 \%] ; \geq 6$ and $\leq 12$ months: $21 \%$ [95\% Cl, $16 \%$ to $25 \%]_{i}>12$ and $\leq 24$ months: $26 \%$ [95\% Cl, 22\% to 31\%]; and >24 months: $34 \%[95 \% \mathrm{Cl}$, 29\% to 39\%]) (Supplementary Figure 10). No differences were 
Table 2. Univariate and multivariate meta-regression analyses of the association of patient and study characteristics with the percentage of patients detected with atrial fibrillation after implantable loop recorder insertion

\begin{tabular}{|c|c|c|c|c|c|c|}
\hline \multirow{2}{*}{ Variable } & \multicolumn{3}{|c|}{ Univariate meta-regression analysis } & \multicolumn{3}{|c|}{ Multivariate meta-regression analysis } \\
\hline & Number & Coefficient (95\% Cl) & $P$ & Number & Coefficient (95\% Cl) & $P$ \\
\hline Age & 30 & 0.013 (0.002 to 0.024$)$ & 0.018 & 30 & $0.009(0.003-0.015)$ & 0.004 \\
\hline Male gender & 29 & $-0.008(-0.018$ to 0.002$)$ & 0.100 & - & - & - \\
\hline Hypertension & 19 & $0.003(-0.002$ to 0.008$)$ & 0.215 & - & - & - \\
\hline Diabetes mellitus & 17 & $0.009(-0.003$ to 0.021$)$ & 0.140 & - & - & - \\
\hline $\mathrm{CHA}_{2} \mathrm{DS}_{2}$-VASc score & 13 & $0.079(-0.058$ to 0.216$)$ & 0.232 & - & - & - \\
\hline Duration of monitoring & 45 & 0.009 (0.005 to 0.013$)$ & $<0.001$ & 30 & $0.015(0.005-0.024)$ & 0.003 \\
\hline Time from event to cardiac monitor implantation & 19 & $0.001(-0.001$ to 0.002$)$ & 0.363 & - & - & - \\
\hline
\end{tabular}

$\mathrm{Cl}$, confidence interval.
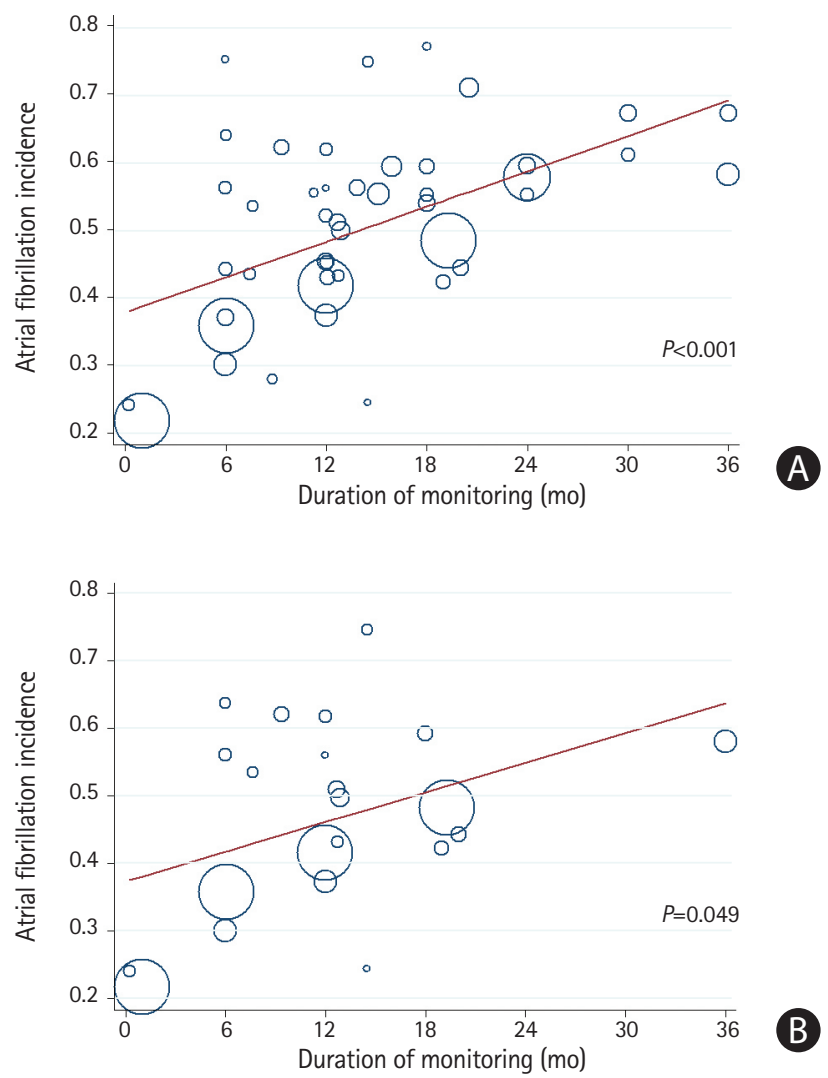

Figure 1. Meta-regression analysis of the association of monitoring duration with the rate of atrial fibrillation (AF) detection with implantable cardiac monitors reported, in (A) all included (abstracts and full publications) studies and (B) fully published studies. AF incidence was calculated using the double arcsine Freeman-Tukey transformation (FTT).

found in the subgroup analyses of all included studies stratified by study type ( $P=0.178$ ) (Supplementary Figure 11$), \mathrm{IS} / \mathrm{TIA}$ subgroup ( $P=0.093$ ) (Supplementary Figure 12), the time threshold used for AF definition ( $P=0.234$ ) (Supplementary Figure 13), the elapsed time from IS/TIA onset to cardiac monitor implantation ( $P>0.999)$ (Supplementary Figure 14) or the device used
$(P=0.174)$ (Supplementary Figure 15). Similarly, in the subgroup analysis of published studies (Supplementary Table 5) there were significant differences ( $P$ for subgroup differences $<0.001$ ) in AF detection rates in subgroups stratified by ICM duration ( $<6$ months: $5 \%$ [95\% Cl, 3\% to $6 \%$ ]; $\geq 6$ and $\leq 12$ months: $22 \%$ [95\% Cl, $16 \%$ to 28\%]; and $>12$ and $\leq 24$ months: $22 \%$ [95\% Cl, 14\% to 29\%]) (Supplementary Figure 16). There were no differences in subgroup analyses of published studies stratified by IS/TIA subtype ( $P=0.429)$ (Supplementary Figure 17$)$, the time threshold used for AF definition ( $P=0.149)$ (Supplementary Figure 18), the elapsed time from IS/TIA onset to cardiac monitor implantation ( $P=0.864)$ (Supplementary Figure $19)$, or the device used $(P=0.174)$ (Supplementary Figure 20). In the aforementioned subgroup analyses, considerable heterogeneity was found within all subgroups $\left(1^{2}>70 \%\right)$, except for the subgroup of studies reporting the 6 min interval as a threshold for AF detection $\left(I^{2}=8 \%\right)$ and the subgroup of studies reporting more than 24 months of ICM duration $\left(I^{2}=24 \%\right)$.

Finally, in a post hoc analysis of available studies, we found that among IS/TIA patients with AF detected during ICM, a total of $87 \%(95 \% \mathrm{Cl}, 78 \%$ to $96 \%)$ experienced asymptomatic AF episodes (Supplementary Figure 21), with no evidence of heterogeneity between studies $\left(I^{2}=29 \%\right.$, $P$ for Cochran $\left.Q=0.21\right)$.

\section{Discussion}

Our meta-analysis showed that AF detection in patients with history of IS/TIA is positively associated only with the duration of ICM and patient age. We failed to find any other independent association between AF detection rates and IS/TIA subtype, device type, other patient characteristics, or elapsed time between IS/TIA onset and cardiac monitor implantation. Approximately nine out of 10 patients, with positive ICM for AF, experienced asymptomatic $\mathrm{AF}$ episodes during the monitoring period. 
Table 3. Subgroup analyses of the association of baseline characteristics with the percentage of patients detected with atrial fibrillation after implantable loop recorder insertion

\begin{tabular}{|c|c|c|c|c|}
\hline Subgroup & Number & AF detection (95\% CI) (\%) & Within subgroup heterogeneity, $I^{2}(\%)$ & Subgroups difference, $P$ \\
\hline \multicolumn{5}{|c|}{ Monitoring duration (mo) } \\
\hline$<6$ & 2 & $5(3-6)$ & 0 & $<0.001$ \\
\hline$\geq 6$ and $\leq 12$ & 19 & $21(16-25)$ & 81 & \\
\hline$>12$ and $\leq 24$ & 20 & $26(22-31)$ & 82 & \\
\hline$>24$ & 4 & $34(29-39)$ & 24 & \\
\hline \multicolumn{5}{|l|}{ IS/TIA subtype } \\
\hline CS & 24 & $21(17-25)$ & 95 & 0.093 \\
\hline ESUS & 14 & $29(23-35)$ & 84 & \\
\hline Unselected & 7 & $23(17-30)$ & 84 & \\
\hline \multicolumn{5}{|l|}{ AF time threshold } \\
\hline$>30 \mathrm{sec}$ & 9 & $17(9-26)$ & 89 & 0.234 \\
\hline$>2 \min$ & 18 & $25(20-30)$ & 97 & \\
\hline$>6$ min & 6 & $25(20-30)$ & 8 & \\
\hline \multicolumn{5}{|c|}{$\begin{array}{l}\text { Time from IS/TIA onset to cardiac monitor } \\
\text { implantation (mo) }\end{array}$} \\
\hline$\leq 1$ & 11 & $23(16-30)$ & 86 & $>0.999$ \\
\hline$>1$ & 10 & $23(15-31)$ & 90 & \\
\hline \multicolumn{5}{|l|}{ Study type } \\
\hline Prospective & 43 & $24(20-27)$ & 95 & 0.178 \\
\hline Retrospective & 2 & 30 (22-38) & 0 & \\
\hline \multicolumn{5}{|l|}{ ICM device } \\
\hline Reveal XT & 10 & $27(21-33)$ & 75 & 0.174 \\
\hline Reveal LINO & 5 & 19 (12-27) & 61 & \\
\hline Reveal XT/LINO & 4 & $28(21-36)$ & 87 & \\
\hline
\end{tabular}

$\mathrm{AF}$, atrial fibrillation; $\mathrm{Cl}$, confidence interval; IS, ischemic stroke; TIA, transient ischemic attack; CS, cryptogenic stroke; ESUS, embolic stroke of undetermined source; ICM, implantable cardiac monitor.

Our findings agree with a previously published systematic review and meta-analysis reporting improved $\mathrm{AF}$ detection with ICM, compared to wearable devices, in CS patients (23.3\% [95\% $\mathrm{Cl}, 13.83 \%$ to $32.29 \%$ ] vs. $13.6 \%[95 \% \mathrm{Cl}, 7.91 \%$ to 19.32\%]; $P$ for subgroup differences $<0.05) .{ }^{49}$ However, compared to the previous meta-analysis, we included a significantly higher number of studies and patients (seven studies with 774 patients vs. 28 studies with 4,531 patients). Moreover, we assessed the potential modifying effect of stroke subtype, baseline characteristics, and time interval between ischemic event and implantation.

AF detection rates in patients with IS/TIA were unrelated to any patient characteristics, except for mean patient age. Although increased age, increased stroke severity, left atrial enlargement, hypertension, congestive heart failure, and valvular heart disease have been associated with increased incidence of AF detection in IS patients, ${ }^{50}$ proposed prediction scores including these parameters have limited diagnostic yield, especially at their middle grades. ${ }^{51}$ Our meta-analysis also provides no further support to the theoretical concern regarding increased AF detection during the immediate post-IS period, due to stroke-induced sympathetic activation. ${ }^{52}$ Finally, the results of subgroup analysis, regarding the time threshold used for AF definition, do not confirm the association of improved ICM performance with increased duration of AF episodes. ${ }^{53}$

Another intriguing finding was that we observed no differences in AF detection rates using ICM, between CS and ESUS patients. This observation challenges the notion that paroxysmal $\mathrm{AF}$ is the main underlying etiopathogenic mechanism of cerebral ischemia in ESUS patients ${ }^{54}$ and is in line with the recently reported New Approach Rivaroxaban Inhibition of Factor $X a$ in a Global Trial versus ASA to Prevent Embolism in Embolic Stroke of Undetermined Source (NAVIGATE ESUS) trial, where the detection rate of symptomatic AF during an approximate 1 -year follow-up period was only $3 \% .^{55}$

Several limitations of the present study need to be acknowl- 
edged. Firstly, it should be noted that baseline characteristics of individual patients (Supplementary Table 2) and study protocol parameters (Table 1) were unavailable in a significant proportion of included studies, and particularly in abstracts from conference proceedings. Moreover, the presence of ecological bias cannot be excluded; thus, the associations of aggregate patient characteristics may not hold true also for individual patient characteristics. Secondly, since this is a studylevel meta-analysis, we could not assess the influence of other parameters on AF detection rates that were not originally provided by included studies, e.g., the recently published hypertension, age, valvular heart disease, peripheral vascular disease, obesity, congestive heart failure, and coronary artery disease (HAVOC) score. ${ }^{49}$ Thirdly, although meta-regression analyses did not provide evidence for any association bet=ween reported study characteristics (except for hypertension history) and $\mathrm{AF}$ detection rate, there is a possibility that heterogeneity in AF incidence could at least partially reflect inherent differences in the patient populations of included studies. Additionally, it should be highlighted that the lack of significant associations could be attributed to the low statistical power, especially for analyses including a low number of studies. Finally, it should be noted that in the present meta-analysis, we did not assess the number of AF episodes, false positive AF episodes, cumulative AF episode duration, or the impact of AF detection in patient management and long-term outcomes. ${ }^{56}$

Our findings challenge current AHA/ASA guidelines, ${ }^{8,9}$ while further highlighting the indispensable role of prolonged rhythm monitoring, using ICM in the identification of a substantial portion of IS/TIA patients with occult AF. According to current recommendations, secondary CS prevention strategies are mainly based on antiplatelet therapy, ${ }_{1}^{6}$ which is known to provide inadequate protection for patients with AF. In these patients, the systemic administration of anticoagulant therapy could contribute to an $8.4 \%$ annual absolute risk reduction of stroke recurrence, compared with antiplatelet therapy. ${ }^{57}$ Also taking into account the negative results of the recent NAVIGATE ESUS trial, showing that rivaroxaban compared to aspirin increases major bleeding without reducing ischemic events in ESUS patients, ${ }^{54}$ ICM emerges as an extremely useful diagnostic tool to identify those patients with occult AF within the heterogeneous group of ESUS or CS patients. ${ }^{58}$ Therefore, prolonged monitoring could have a substantial impact on the secondary prevention of CS patients with underlying $A F$, leading to prompt anticoagulant initiation and lower stroke recurrence. ${ }^{59}$ The Detection of Silent Atrial Fibrillation aFter Ischemic StrOke (SAFFO) study, guided by implantable loop recorder ${ }^{60}$ and the AF detected by continuous electrocardiographic monitoring using implantable loop re- corder to prevent stroke in individuals at risk (LOOP) study ${ }^{61}$ are two ongoing, multicenter, open-label RCTs, that aim to evaluate health benefits, including reduction of recurrent ischemic events and cost-effectiveness of ICM in secondary stroke prevention. Results from these studies will further characterize the target population for ICM, the optimal threshold for AF definition and whether ICM monitoring results in lower stroke recurrence through anticoagulant initiation.

In conclusion, the results of the present meta-analysis support extended-duration ICM monitoring as a reasonable option for patients with IS or TIA, and initial negative screening for AF detection, ${ }_{1}^{62}$ that may substantially enhance detection of predominantly subclinical AF episodes.

\section{Supplementary materials}

Supplementary materials related to this article can be found online at https://doi.org/10.5853/jos.2019.01067.

\section{Disclosure}

The authors have no financial conflicts of interest.

\section{References}

1. Sacco RL, Ellenberg JH, Mohr JP, Tatemichi TK, Hier DB, Price $T R$, et al. Infarcts of undetermined cause: the NINCDS Stroke Data Bank. Ann Neurol 1989;25:382-390.

2. Petty GW, Brown RD Jr, Whisnant JP, Sicks JD, O'Fallon WM, Wiebers DO. Ischemic stroke subtypes: a population-based study of incidence and risk factors. Stroke 1999;30:25132516.

3. Kolominsky-Rabas PL, Weber M, Gefeller $\mathrm{O}$, Neundoerfer $\mathrm{B}$, Heuschmann PU. Epidemiology of ischemic stroke subtypes according to TOAST criteria: incidence, recurrence, and longterm survival in ischemic stroke subtypes: a populationbased study. Stroke 2001;32:2735-2740.

4. Tsang TS, Petty GW, Barnes ME, O'Fallon WM, Bailey KR, Wiebers DO, et al. The prevalence of atrial fibrillation in incident stroke cases and matched population controls in Rochester, Minnesota: changes over three decades. J Am Coll Cardiol 2003;42:93-100.

5. Wolf PA, Abbott RD, Kannel WB. Atrial fibrillation as an independent risk factor for stroke: the Framingham Study. Stroke 1991;22:983-988.

6. Sanna T, Diener HC, Passman RS, Di Lazzaro V, Bernstein RA, Morillo $C A$, et al. Cryptogenic stroke and underlying atrial fibrillation. N Eng/ J Med 2014;370:2478-2486. 
7. Sposato LA, Cipriano LE, Saposnik G, Ruíz Vargas E, Riccio PM, Hachinski V. Diagnosis of atrial fibrillation after stroke and transient ischaemic attack: a systematic review and meta-analysis. Lancet Neurol 2015;14:377-387.

8. Kernan WN, Ovbiagele B, Black HR, Bravata DM, Chimowitz MI, Ezekowitz MD, et al. Guidelines for the prevention of stroke in patients with stroke and transient ischemic attack: a guideline for healthcare professionals from the American Heart Association/American Stroke Association. Stroke 2014;45:2160-2236.

9. Powers WJ, Rabinstein AA, Ackerson T, Adeoye OM, Bambakidis NC, Becker K, et al. 2018 Guidelines for the early management of patients with acute ischemic stroke: a guideline for healthcare professionals from the American Heart Association/American Stroke Association. Stroke 2018; 49:e46-e110.

10. Reiffel JA, Verma A, Kowey PR, Halperin JL, Gersh BJ, Wachter $\mathrm{R}$, et al. Incidence of previously undiagnosed atrial fibrillation using insertable cardiac monitors in a high-risk population: the REVEAL AF Study. JAMA Cardiol 2017;2:1120-1127.

11. Liberati A, Altman DG, Tetzlaff J, Mulrow C, Gøtzsche PC, loannidis JP, et al. The PRISMA statement for reporting systematic reviews and meta-analyses of studies that evaluate health care interventions: explanation and elaboration. J Clin Epidemiol 2009;62:e1-e34.

12. Wells GA, Shea B, O'Connell D, Peterson J, Welch V, Losos M, et al. The Newcastle-Ottawa Scale (NOS) for assessing the quality if nonrandomized studies in meta-analyses. The Ottawa Hospital Research Institute. http://www.ohri.ca/programs/clinical_epidemiology/oxford.htm. 2019. Assessed July 3, 2019.

13. Deeks JJ, Higgins JP, Altman DG. Chapter 9.6.4: Meta-regression. In: Higgins JP, Green S, editors. Cochrane Handbook for Systematic Reviews of Interventions. Hoboken, NJ: Wiley, 2011. https://handbook-5-1.cochrane.org/chapter_9/9_6_4_ meta_regression.htm. Assessed July 3, 2019.

14. Freeman MF, Tukey JW. Transformations related to the angular and the square root. Ann Math Stat 1950;21:607-11.

15. IntHout J, loannidis JP, Borm GF. The Hartung-Knapp-SidikJonkman method for random effects meta-analysis is straightforward and considerably outperforms the standard DerSimonian-Laird method. BMCMed Res Methodol 2014;14:25.

16. Feinberg WM, Blackshear JL, Laupacis A, Kronmal R, Hart RG. Prevalence, age distribution, and gender of patients with atrial fibrillation. Analysis and implications. Arch Intern Med 1995;155:469-473.

17. Deeks JJ, Higgins JP, Altman DG. Chapter 9: Analyzing data and undertaking meta-analyses. In: Higgins JP, Green S, edi- tors. Cochrane Handbook for Systematic Reviews of Interventions. Hoboken, NJ: Wiley, 2011. https://handbook-5-1. cochrane.org/chapter_9/9_analysing_data_and_undertaking_meta_analyses.htm. Assessed July 3, 2019.

18. Borenstein M, Hedges LV, Higgins JPT, Rothstein HR. Introduction to Meta-Analysis. Chichester, UK: John Wiley \& Sons, 2008.

19. Sterne JA, Sutton AJ, loannidis JP, Terrin N, Jones DR, Lau J, et al. Recommendations for examining and interpreting funnel plot asymmetry in meta-analyses of randomized controlled trials. BMJ 2011;343:d4002.

20. Wallace BC, Dahabreh IJ, Trikalinos TA, Lau J, Trow P, Schmid $\mathrm{CH}$. Closing the gap between methodologists and end-users: R as a computational back-end. J Stat Softw 2012;49:1-15.

21. Asaithambi G, Monita JE, Hanson SK. Abstract WP231: Predictors for early atrial fibrillation detection among cryptogenic stroke patients with insertable cardiac monitors: a single-center experience. Stroke 2017;48(Suppl 1):AWP231.

22. Carrazco C, Golyan D, Kahen M, Black K, Libman RB, Katz JM. Prevalence and risk factors for paroxysmal atrial fibrillation and flutter detection after cryptogenic ischemic stroke. $J$ Stroke Cerebrovasc Dis 2018;27:203-209.

23. Ching MI, Zhang $C_{\text {, Vaughn }} C_{\text {, Lail }} N_{\text {, Leahy }}$, Kandel $A$, et al. Abstract WP199: Left atrial volume index and PR interval are independent predictors of atrial fibrillation in embolic stroke patients with insertable cardiac monitor. Stroke 2018;49 (Suppl 1):AWP199.

24. Cotter PE, Martin PJ, Ring L, Warburton EA, Belham M, Pugh PJ. Incidence of atrial fibrillation detected by implantable loop recorders in unexplained stroke. Neurology 2013;80: 1546-1550.

25. Passman RS, Rymer MM, Liu S, Ziegler PD. Abstract 78: Incidence of atrial fibrillation among patients with an embolic stroke of undetermined source. Stroke 2017;48(Suppl 1):A78.

26. de Lera M, Largaespada G, Cortijo E, Sandin M, Calleja A, Garcia $E_{1}$ et al. AS18-008: Predictors of higher arrhytmic load in patients with cryptogenic stroke and covert atrial fibrillation detected by implantable loop recorders. Eur Stroke J 2016;1(1 Suppl):641.

27. Dion F, Saudeau D, Bonnaud I, Friocourt P, Bonneau A, Poret $P$, et al. Unexpected low prevalence of atrial fibrillation in cryptogenic ischemic stroke: a prospective study. J Interv Card Electrophysio/ 2010;28:101-107.

28. Etgen $T$, Hochreiter $M$, Mundel $M$, Freudenberger T. Insertable cardiac event recorder in detection of atrial fibrillation after cryptogenic stroke: an audit report. Stroke 2013;44:20072009.

29. Israel C, Kitsiou A, Kalyani M, Deelawar S, Ejangue LE, Ro- 
galewski $A_{1}$ et al. Detection of atrial fibrillation in patients with embolic stroke of undetermined source by prolonged monitoring with implantable loop recorders. Thromb Haemost 2017;117:1962-1969.

30. Jorfida M, Antolini M, Cerrato E, Caprioli MG, Castagno D, Garrone $\mathrm{P}$, et al. Cryptogenic ischemic stroke and prevalence of asymptomatic atrial fibrillation: a prospective study. J Cardiovasc Med (Hagerstown) 2016;17:863-869.

31. Kamel H, Yaghi S, Passman R, Allred J, Sarkar S, Kohler J, et al. AS21-004: Comparison of atrial fibrillation diagnosis and oral anticoagulation utilization among ischemic stroke patients with vs. without insertable cardiac monitors. Eur Stroke J 2018;3(1 Suppl):452.

32. Katz JM, Gribko M, Jadonath $R$, Arora $R$, Salamon E, Garlitzki A, et al. Abstract WMP63: Prevalence of occult paroxysmal atrial fibrillation in non-cryptogenic ischemic stroke patients. Stroke 2017;48(Suppl 1):AWMP63.

33. Kotlarz-Böttcher MJ, Busch $M$, Frenzel $M$, Hummel $A$, Schminke U, von Sarnowski B. AS21-019: Risk factors for atrial fibrillation in patients with embolic stroke of undetermined source (ESUS). Eur Stroke J 2018;3(1 Suppl):457.

34. Makimoto $H$, Kurt M, Gliem M, Lee Jl, Schmidt J, Müller P, et al. High incidence of atrial fibrillation after embolic stroke of undetermined source in posterior cerebral artery territory. $J$ Am Heart Assoc 2017;6:e007448.

35. Navarro Pérez MP, Pérez Lázaro C, Pelegrín Díaz J, Rodrigo Trallero G, Sánchez Val A, Garcés Antón E, et al. AS21-031: Paroxysmal atrial fibrillation detection after cryptogenic stroke: a single center experience. Eur Stroke J 2018;3(1 Suppl):460.

36. Noone I, Meagher MK, Mc Creery C, Cassidy T. AS18-027: The role of loop recorders in embolic stroke of uncertain source (ESUS). Eur Stroke J 2016;1 (1 Suppl):16.

37. Pallesen LPM, Mayer J, Barlinn K, Barlinn J, Prakapenia A, Sieppmann T, et al. Abstract WP230: Real-life detection rate of insertable cardiac monitors in patients with ESUS. Stroke 2017;48(Suppl 1):AWP230.

38. Poli S, Diedler J, Härtig F, Götz N, Bauer A, Sachse T, et al. Insertable cardiac monitors after cryptogenic stroke: a risk factor based approach to enhance the detection rate for paroxysmal atrial fibrillation. Eur J Neurol 2016;23:375-381.

39. Elkind MS, Wachter R, Verma A, Kowey PR, Halperin JL, Gersh BJ, et al. Abstract 189: Identifying patients at highest risk of developing atrial fibrillation and the role of remote prior stroke: insights from the REVEAL AF study. Stroke 2018;49 (Suppl 1):A189.

40. Ritter MA, Kochhäuser $S$, Duning T, Reinke F, Pott $C_{\text {, }}$ Dechering $D G$, et al. Occult atrial fibrillation in cryptogenic stroke: detection by 7-day electrocardiogram versus implantable cardiac monitors. Stroke 2013;44:1449-1452.

41. Rodríguez-Campello A, Cuadrado-Godia E, Ois A, Giralt-

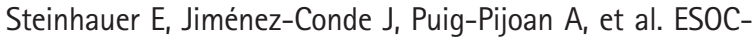
1467: Early detection of atrial fibrillation in embolic stroke of unknown origin (ESUS). Int J Stroke 2015;10:268-269.

42. Rojo-Martinez E, Sandín-Fuentes M, Calleja-Sanz Al, CortijoGarcía E, García-Bermejo P, Ruiz-Piñero M, et al. High performance of an implantable Holter monitor in the detection of concealed paroxysmal atrial fibrillation in patients with cryptogenic stroke and a suspected embolic mechanism. Rev Neurol 2013;57:251-257.

43. Sethi P, Biby S, Allred J, Seiler A, Xu J. AS18-067: Surveillance for atrial fibrillation in patients with cryptogenic stroke using an implantable loop recorder during an inpatient hospitalization in a community hospital setting. Eur Stroke J 2017;2(1 Suppl):115.

44. Joseph K, Wanjiku S, Jumaa M, Richards M. Abstract W P194: Improved efficacy of ICM detection of atrial fibrillation in cryptogenic stroke patients with MRI-defined infarcts: preliminary results from the SPIDER registry. Stroke 2015;46(Suppl 1):AWP194.

45. Christensen LM, Krieger DW, Højberg S, Pedersen OD, Karlsen FM, Jacobsen MD, et al. Paroxysmal atrial fibrillation occurs often in cryptogenic ischaemic stroke. Final results from the SURPRISE study. Eur J Neurol 2014;21:884-889.

46. Reinke F, Bettin M, Ross LS, Kochhäuser S, Kleffner I, Ritter $M$, et al. Refinement of detecting atrial fibrillation in stroke patients: results from the TRACK-AF Study. Eur J Neurol 2018;25:631-636

47. Ziegler PD, Rogers JD, Ferreira SW, Nichols AJ, Sarkar S, Koehler JL, et al. Real-world experience with insertable cardiac monitors to find atrial fibrillation in cryptogenic stroke. Cerebrovasc Dis 2015;40:175-181.

48. Ziegler PD, Rogers JD, Ferreira SW, Nichols AJ, Richards M, Koehler $\mathrm{JL}$, et al. Long-term detection of atrial fibrillation with insertable cardiac monitors in a real-world cryptogenic stroke population. Int J Cardiol 2017;244:175-179.

49. Afzal MR, Gunda S, Waheed S, Sehar N, Maybrook RJ, Dawn $B$, et al. Role of outpatient cardiac rhythm monitoring in cryptogenic stroke: a systematic review and meta-analysis. Pacing Clin Electrophysiol 2015;38:1236-1245.

50. Kwong C, Ling AY, Crawford MH, Zhao SX, Shah NH. A clinical score for predicting atrial fibrillation in patients with cryptogenic stroke or transient ischemic attack. Cardiology 2017;138:133-140.

51. Andrade JG, Field T, Khairy P. Detection of occult atrial fibrillation in patients with embolic stroke of uncertain source: a work in progress. Front Physiol 2015;6:100. 
52. Katsanos AH, Korantzopoulos P, Tsivgoulis G, Kyritsis AP, Kosmidou M, Giannopoulos S. Electrocardiographic abnormalities and cardiac arrhythmias in structural brain lesions. Int J Cardiol 2013;167:328-334.

53. Lee $\mathrm{R}$, Mittal S. Utility and limitations of long-term monitoring of atrial fibrillation using an implantable loop recorder. Heart Rhythm 2018;15:287-295.

54. Hart RG, Diener HC, Coutts SB, Easton JD, Granger CB, O'Donnell MJ, et al. Embolic strokes of undetermined source: the case for a new clinical construct. Lancet Neurol 2014; 13:429-438.

55. Hart RG, Sharma M, Mundl H, Kasner SE, Bangdiwala SI, Berkowitz SD, et al. Rivaroxaban for stroke prevention after embolic stroke of undetermined source. N Engl J Med 2018; 378:2191-2201.

56. Hart RG, Benavente O, McBride R, Pearce LA. Antithrombotic therapy to prevent stroke in patients with atrial fibrillation: a meta-analysis. Ann Intern Med 1999;131:492-501.

57. Katsanos $A H$, Bhole R, Frogoudaki A, Giannopoulos S, Goyal $N$, Vrettou $A R$, et al. The value of transesophageal echocardiography for embolic strokes of undetermined source. Neurology 2016;87:988-995.

58. Wechselberger S, Kronborg M, Huo Y, Piorkowski J, Neudeck S,
Päßler $E_{1}$ et al. Continuous monitoring after atrial fibrillation ablation: the LINQ AF study. Europace 2018;20:f312-f320.

59. Tsivgoulis G, Katsanos AH, Mac Grory B, Köhrmann M, Ricci BA, Tsioufis $K$, et al. (AS25-022) Prolonged cardiac rhythm monitoring and secondary stroke prevention in patients with cryptogenic cerebral ischemia: a systematic review and meta-analysis. Eur Stroke J 2019;4(1 Suppl):178.

60. Toni D, Lorenzano S, Strano S; SAFFO Trial Investigators. Detection of Silent Atrial Fibrillation aFter Ischemic StrOke (SAFFO) guided by implantable loop recorder: multicentre Italian trial based on stroke unit network with paired cardioarrhythmology units (Italian Neurocardiology Unit Network). Int J Stroke 2016;11:361-367.

61. Diederichsen SZ, Haugan KJ, Køber L, Højberg S, Brandes A,

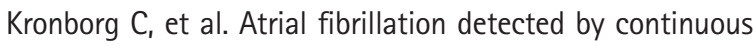
electrocardiographic monitoring using implantable loop recorder to prevent stroke in individuals at risk (the LOOP study): rationale and design of a large randomized controlled trial. Am Heart J 2017;187:122-132.

62. Albers GW, Bernstein RA, Brachmann J, Camm J, Easton JD, Fromm $\mathrm{P}$, et al. Heart rhythm monitoring strategies for cryptogenic stroke: 2015 diagnostics and monitoring stroke focus group report. J Am Heart Assoc 2016;5:e002944. 


\section{Supplementary Methods}

\section{Complete MEDLINE search algorithm}

((("heart"[MeSH Terms] OR "heart"[All Fields] OR "cardiac"[All Fields]) AND monitoring[All Fields]) OR (insertable[All Fields] AND loop[All Fields] AND ("recorder"[All Fields]) OR (implantable[All Fields] AND cardiac[All Fields] AND monitoring[All Fields] AND ((cryptogenic[All Fields] AND ("stroke"[MeSH Terms] OR "stroke"[All Fields])) OR (("ischemia"[MeSH Terms] OR "ischemia"[All Fields] OR "ischemic"[All Fields]) AND ("stroke"[MeSH Terms] OR "stroke"[All Fields])) OR (("embolism"[MeSH Terms] OR "embolism"[All Fields] OR "embolic"[All Fields]) AND ("stroke"[MeSH Terms] OR "stroke"[All Fields]) AND undetermined[All Fields] AND ("Source Notes Hist Art"[Journal] OR "source"[All Fields])) OR ("cerebral ischemia"[All Fields] OR "cerebral infarction"[MeSH Terms] OR ("cerebral"[All Fields] AND "infarction"[All Fields]) OR "cerebral infarction"[All Fields] OR ("cerebral"[All Fields] AND "ischemia"[All Fields]) OR "cerebral ischemia"[All Fields] OR "brain ischemia"[MeSH Terms] OR ("brain"[All Fields] AND "ischemia"[All Fields]) OR "brain ischemia"[All Fields] OR ("cerebral"[All Fields] AND "ischemia"[All Fields])) AND (("atrial fibrillation"[MeSH Terms] OR ("atrial"[All Fields] AND "fibrillation"[All Fields]) OR "atrial fibrillation"[All Fields]) OR ("atrial flutter"[MeSH Terms] OR ("atrial"[All Fields] AND "flutter"[All Fields]) OR "atrial flutter"[All Fields]))

Supplementary Table 1. Excluded studies with reasons for exclusion

\begin{tabular}{|c|c|}
\hline Study & Reasons for exclusion \\
\hline de Lera et al. (2017) ${ }^{1}$ & Overlapping data \\
\hline Favilla et al. (2015) ${ }^{2}$ & Monitoring with device other than ICM \\
\hline Friberg et al. (2014) ${ }^{3}$ & Monitoring with device other than ICM \\
\hline Giralt-Steinhauer et al. $(2015)^{4}$ & Monitoring with device other than ICM \\
\hline Kitsiou et al. $(2015)^{5}$ & Overlapping data \\
\hline Kitsiou et al. (2016) ${ }^{6}$ & Overlapping data \\
\hline Pedersen et al. (2016) ${ }^{7}$ & Monitoring with device other than ICM \\
\hline Prakapenia et al. (2017) ${ }^{8}$ & Monitoring duration not available \\
\hline Perera et al. $(2016)^{9}$ & Monitoring with device other than ICM \\
\hline Rem et al. $(1985)^{10}$ & Monitoring with device other than ICM \\
\hline Ricci et al. (2018) & Monitoring with device other than ICM \\
\hline Rizos et al. (2015) ${ }^{12}$ & Monitoring with device other than ICM \\
\hline Rodríguez-Campello et al. (2018) ${ }^{13}$ & Monitoring duration not available \\
\hline Rojo et al. (2015) $)^{14}$ & Overlapping data \\
\hline Schneider et al. (2016) $)^{15}$ & Monitoring duration not available \\
\hline Sposato et al. $(2012)^{16}$ & Monitoring with device other than ICM \\
\hline Stahrenberg et al. (2010) $)^{17}$ & Monitoring with device other than ICM \\
\hline Yetim et al. (2016) ${ }^{18}$ & Monitoring with device other than ICM \\
\hline
\end{tabular}

ICM, implantable cardiac monitor. 
Supplementary Table 2. Characteristics of patients in included studies

\begin{tabular}{|c|c|c|c|c|c|c|c|c|c|c|c|c|c|}
\hline Study & $\begin{array}{l}\text { Stroke } \\
(\%)\end{array}$ & $\begin{array}{l}\text { Age } \\
(y r)\end{array}$ & $\begin{array}{l}\text { Male } \\
(\%)\end{array}$ & $\begin{array}{l}\text { HTN } \\
(\%)\end{array}$ & $\begin{array}{l}\text { DM } \\
(\%)\end{array}$ & $\begin{array}{l}\text { CHF } \\
(\%)\end{array}$ & $\begin{array}{l}\text { VD } \\
(\%)\end{array}$ & $\begin{array}{l}\text { HLP } \\
(\%)\end{array}$ & $\begin{array}{l}\text { Previous } \\
\text { stroke }(\%)\end{array}$ & $\begin{array}{l}\mathrm{CHADS}_{2} \\
\text { score }\end{array}$ & $\begin{array}{l}\mathrm{CHA}_{2} \mathrm{DS}_{2-} \\
\text { VASc score }\end{array}$ & $\begin{array}{c}\text { Asymptomatic } \\
(\%)\end{array}$ & $\begin{array}{l}\text { Lost to fol- } \\
\text { low-up (\%) }\end{array}$ \\
\hline Asaithambi et al. (2017) $)^{19 *}$ & NA & NA & NA & 76 & NA & NA & NA & NA & NA & NA & NA & NA & NA \\
\hline Carrazco et al. $(2018)^{20}$ & 100 & 66 & 47 & 78 & 27 & 4 & NA & 68 & 15 & NA & NA & NA & NA \\
\hline Ching et al. $(2018)^{21 *}$ & 100 & 70 & NA & NA & NA & NA & NA & NA & NA & NA & NA & NA & NA \\
\hline Cotter et al. $(2013)^{22}$ & 100 & $51 \pm 14$ & 54.9 & NA & NA & NA & NA & NA & NA & $2(2-3)$ & $3(2-4)$ & 92 & 0 \\
\hline CRYSTAL-AF (2014) & 90.5 & $62 \pm 11$ & 64.3 & 65.2 & 15.4 & NA & NA & 56.6 & 16.7 & $3(2-4)$ & NA & 79 & 5.4 \\
\hline CRYSTAL-AF (2017) & 100 & NA & NA & NA & NA & NA & NA & NA & NA & NA & NA & NA & NA \\
\hline de Lera et al. $(2016)^{25 *}$ & 100 & 67 & 55 & NA & NA & NA & NA & NA & NA & NA & NA & NA & NA \\
\hline Dion et al. $(2010)^{26}$ & 100 & $49 \pm 14$ & 62.5 & 29.2 & 0 & NA & NA & 33.3 & NA & NA & NA & 100 & 0 \\
\hline Etgen et al. $(2013)^{27}$ & 100 & 61.6 & 50 & 63.6 & 9.1 & NA & NA & 72.7 & NA & NA & NA & 67 & 0 \\
\hline Israel et al. $(2017)^{28}$ & 100 & $65 \pm 9$ & 61.1 & 82.9 & 24.4 & NA & 33.3 & NA & NA & NA & $4.5 \pm 1.3$ & NA & 0 \\
\hline Jorfida et al. (2016) ${ }^{29}$ & 100 & $68 \pm 9$ & 57.4 & 88.7 & 18.5 & NA & NA & NA & 27.8 & $3.4 \pm 0.8$ & $4.5 \pm 1.2$ & 76 & 0 \\
\hline Kamel et al. (2018) ${ }^{30 *}$ & NA & NA & NA & NA & NA & NA & NA & NA & NA & NA & NA & NA & NA \\
\hline Katz et al. $(2017)^{31 *}$ & NA & 65 & 68.1 & NA & NA & NA & NA & NA & NA & 3.5 & 4.5 & NA & NA \\
\hline $\begin{array}{l}\text { Kotlarz-Böttcher et al. } \\
(2018)^{32 *}\end{array}$ & 100 & NA & NA & NA & NA & NA & NA & NA & NA & NA & NA & NA & NA \\
\hline Makimoto et al. $(2017)^{33}$ & 100 & $62 \pm 12$ & 58 & 73 & 16 & NA & 12 & NA & NA & NA & $4.1 \pm 1.3$ & NA & 0 \\
\hline $\begin{array}{l}\text { Navarro Pérez et al. } \\
(2018)^{34 *}\end{array}$ & NA & 74.4 & 56.8 & NA & NA & NA & NA & NA & NA & NA & NA & NA & NA \\
\hline Noone et al. $(2016)^{35 *}$ & 100 & NA & NA & 41.7 & 7.5 & NA & 23.6 & 74.8 & 56.3 & NA & NA & NA & NA \\
\hline Pallesen et al. $(2017)^{36 *}$ & 100 & 61 & 64 & NA & NA & NA & NA & NA & NA & NA & NA & NA & NA \\
\hline Poli et al. $(2016)^{37}$ & 89 & $66 \pm 12$ & 47 & 79 & 15 & NA & 36 & NA & NA & NA & $5(4-6)$ & 92 & 0 \\
\hline REVEAL-AF (2018) $)^{38 *}$ & 100 & - & - & - & - & - & - & - & - & - & - & - & - \\
\hline Ritter et al. $(2013)^{39}$ & 100 & $\begin{array}{c}63 \\
(48-72)\end{array}$ & 57 & 70 & 11.6 & 0 & 13.3 & NA & NA & $3(2-3)$ & $4(3-5)$ & NA & 1.6 \\
\hline $\begin{array}{l}\text { Rodríguez-Campello et al. } \\
(2015)^{40 *}\end{array}$ & 100 & $75 \pm 9$ & 60.7 & 64.3 & NA & NA & NA & NA & NA & NA & NA & NA & NA \\
\hline $\begin{array}{l}\text { Rojo-Martinez et al. } \\
(2013)^{41}\end{array}$ & 90.1 & $67 \pm 13$ & 46.5 & 55.4 & 19.8 & NA & 20.9 & 52.5 & NA & NA & $4.51 \pm 1.54$ & NA & NA \\
\hline Sethi et al. $(2017)^{42 *}$ & 100 & 67.9 & 53.6 & NA & NA & NA & NA & NA & NA & NA & NA & NA & NA \\
\hline SPIDER Registry $(2015)^{43 *}$ & NA & $67 \pm 13$ & 59.4 & NA & NA & NA & NA & NA & NA & NA & NA & NA & NA \\
\hline SURPRISE (2014) ${ }^{44}$ & 72.3 & 57 & 55.1 & 45.3 & 6.9 & NA & NA & NA & NA & 2 & 3 & 100 & 8.4 \\
\hline TRACK-AF (2018) $)^{45}$ & 81.9 & $64 \pm 13$ & 56.2 & NA & NA & NA & NA & NA & NA & NA & $4(3-6)$ & NA & 0 \\
\hline $\begin{array}{l}\text { Ziegler et al. }(2015)^{46} \\
(2017)^{47}\end{array}$ & NA & $65 \pm 13$ & 53 & NA & NA & NA & NA & NA & NA & NA & NA & NA & 0 \\
\hline
\end{tabular}

Values are presented as mean \pm standard deviation or median (interquartile range).

HTN, hypertension; DM, diabetes mellitus; CHF, congestive heart failure; VD, vascular disease; HLP, hyperlipidemia; NA, not available; CRYSTAL-AF, Cryptogenic Stroke and underlying Atrial Fibrillation; REVEAL AF, Incidence of AF in High Risk Patients; SPIDER Registry, Stroke Prevention through the Improved Detection of AF registry; SURPRISE, Stroke Prior to Diagnosis of Atrial Fibrillation Using Long-term Observation with Implantable Cardiac Monitoring Apparatus Reveal; TRACK-AF, Follow-up of Kryptogenic Stroke Patients With Implantable vs. Non-invasive Devices to Detect Atrial Fibrillation.

*Available only as abstracts. 
Supplementary Table 3. Quality assessment of included studies

\begin{tabular}{|c|c|c|c|c|}
\hline Study & Selection & Comparability & Outcome & Overall \\
\hline Carrazco et al. $(2018)^{20}$ & $3^{*}$ & NA & $3^{*}$ & $6 / 7$ \\
\hline Cotter et al. $(2013)^{22}$ & $3^{*}$ & NA & $3^{*}$ & $6 / 7$ \\
\hline CRYSTAL-AF (2014) ${ }^{23}$ & $4^{*}$ & NA & $3^{*}$ & $7 / 7$ \\
\hline Dion et al. $(2010)^{26}$ & $3^{*}$ & NA & $2^{*}$ & $5 / 7$ \\
\hline Etgen et al. $(2013)^{27}$ & $3^{*}$ & NA & $2^{*}$ & $5 / 7$ \\
\hline Israel et al. $(2017)^{28}$ & $4^{*}$ & NA & $2^{*}$ & $6 / 7$ \\
\hline Jorfida et al. (2016) ${ }^{29}$ & $4^{*}$ & NA & $2^{*}$ & $6 / 7$ \\
\hline Makimoto et al. (2017) & $3^{*}$ & NA & $2^{*}$ & $5 / 7$ \\
\hline Poli et al. $(2016)^{37}$ & $4^{*}$ & NA & $3^{*}$ & $7 / 7$ \\
\hline Ritter et al. $(2013)^{39}$ & $3^{*}$ & NA & $3^{*}$ & $6 / 7$ \\
\hline Rojo-Martinez et al. $(2013)^{41}$ & $3^{*}$ & NA & $3^{*}$ & $6 / 7$ \\
\hline SURPRISE $(2014)^{44}$ & $3^{*}$ & NA & $3^{*}$ & $6 / 7$ \\
\hline TRACK-AF (2018) ${ }^{45}$ & $3^{*}$ & NA & $3^{*}$ & $6 / 7$ \\
\hline Ziegler et al. $(2015)^{46}$ & $3^{*}$ & NA & $2^{*}$ & $5 / 7$ \\
\hline Ziegler et al. $(2017)^{47}$ & $46 / 56$ & NA & $36 / 42$ & $82 / 98$ \\
\hline
\end{tabular}

NA, not applicable; CRYSTAL-AF, Cryptogenic Stroke and underlying Atrial Fibrillation; SURPRISE, Stroke Prior to Diagnosis of Atrial Fibrillation Using Longterm Observation with Implantable Cardiac Monitoring Apparatus Reveal; TRACK-AF, Follow-up of Kryptogenic Stroke Patients With Implantable vs. Non-invasive Devices to Detect Atrial Fibrillation.

*Number of stars awarded for each category.

Supplementary Table 4. Univariate and multivariate meta-regression analyses of fully published studies on the association of monitoring duration and individual patient characteristics with the rate of atrial fibrillation detection using implantable cardiac monitoring

\begin{tabular}{|c|c|c|c|c|c|c|}
\hline \multirow{2}{*}{ Variable } & \multicolumn{3}{|c|}{ Univariate meta-regression analysis } & \multicolumn{3}{|c|}{ Multivariate meta-regression analysis } \\
\hline & Number & Coefficient (95\% Cl) & $P$ & Number & Coefficient (95\% Cl) & $P$ \\
\hline Age & 22 & $0.011(-0.003$ to 0.025$)$ & 0.110 & 16 & $0.037(0.013 \text { to } 0.062)^{*}$ & 0.007 \\
\hline Male sex & 22 & $-0.008(-0.019$ to 0.003$)$ & 0.136 & - & - & \\
\hline Hypertension & 16 & 0.005 (0.001 to 0.010$)$ & 0.029 & 16 & $-0.006(-0.019$ to 0.007$)$ & 0.353 \\
\hline Diabetes mellitus & 16 & 0.013 (0.001 to 0.024) & 0.033 & 16 & $-0.001(-0.007$ to 0.005$)$ & 0.775 \\
\hline $\mathrm{CHA}_{2} \mathrm{DS}_{2}$ VASc score & 12 & $0.094(-0.028$ to 0.216$)$ & 0.118 & - & - & \\
\hline Duration of monitoring & 22 & 0.007 (0.001 to 0.014$)$ & 0.049 & 16 & 0.009 (0.003 to 0.015$)$ & 0.006 \\
\hline $\begin{array}{l}\text { Time from event to cardiac monitor } \\
\text { implantation }\end{array}$ & 16 & $0.001(-0.001$ to 0.002$)$ & 0.492 & - & - & \\
\hline
\end{tabular}

$\mathrm{Cl}$, confidence interval.

*Mean patient age was included in the multivariate analysis as an a priori potential confounder. 
Supplementary Table 5. Subgroup analyses of fully published studies on the association of monitoring duration and individual patient characteristics with the rate of atrial fibrillation detection using implantable cardiac monitors

\begin{tabular}{|c|c|c|c|c|}
\hline Subgroup & Number & AF detection (95\% CI) (\%) & Within subgroup heterogeneity, $I^{2}(\%)$ & Subgroup differences, $P$ \\
\hline \multicolumn{5}{|c|}{ Monitoring duration (mo) } \\
\hline$<6$ & 2 & $5(3-6)$ & 0 & $<0.001$ \\
\hline$\geq 6$ and $\leq 12$ & 10 & $22(16-28)$ & 87 & \\
\hline$>12$ and $\leq 24$ & 9 & $22(14-29)$ & 80 & \\
\hline \multicolumn{5}{|l|}{ IS/TIA subtype } \\
\hline CS & 20 & $20(15-26)$ & 95 & 0.429 \\
\hline ESUS & 2 & $23(18-28)$ & 0 & \\
\hline \multicolumn{5}{|l|}{ AF time threshold } \\
\hline$>30 \mathrm{sec}$ & 8 & $15(9-21)$ & 88 & 0.149 \\
\hline$>2 \min$ & 11 & $21(16-27)$ & 97 & \\
\hline \multicolumn{5}{|c|}{$\begin{array}{l}\text { Time from IS/TIA onset to cardiac monitor } \\
\text { implantation (mo) }\end{array}$} \\
\hline$<1$ & 8 & $22(15-29)$ & 84 & 0.864 \\
\hline$>1$ & 9 & $23(14-32)$ & 91 & \\
\hline \multicolumn{5}{|l|}{ ICM device } \\
\hline Reveal XT & 9 & $26(19-32)$ & 70 & 0.174 \\
\hline Reveal XT/LINO & 2 & $32(25-39)$ & 0 & \\
\hline
\end{tabular}

$\mathrm{AF}$, atrial fibrillation; $\mathrm{Cl}$, confidence interval; IS, ischemic stroke; TIA, transient ischemic attack; $C$, cryptogenic stroke; ESUS, embolic stroke of undetermined source; ICM, implantable cardiac monitor. 

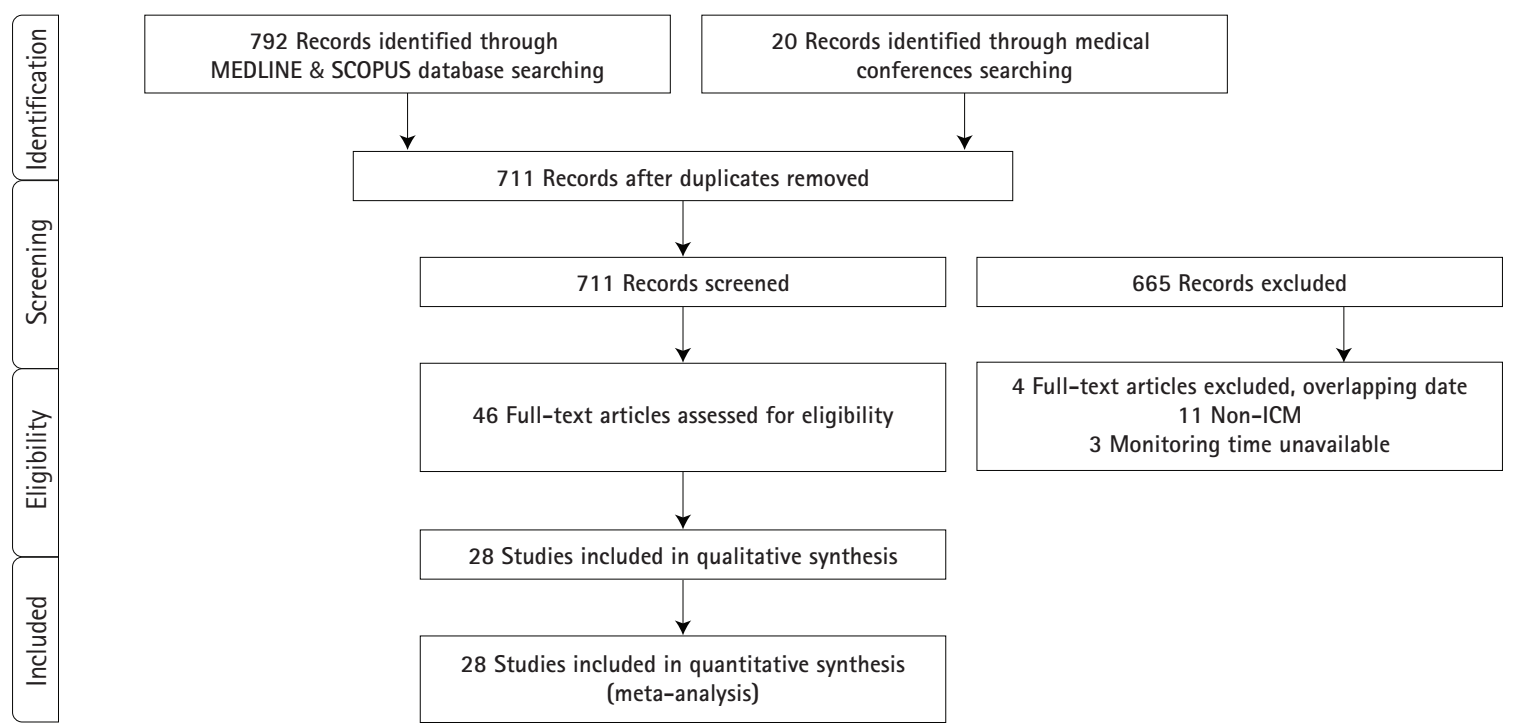

Supplementary Figure 1. Flow chart summarizing the selection procedure for eligible studies. ICM, implantable cardiac monitor. 
Studies

Ritter et al (2)

Etgen et al

Cotter et al

SURPRISE

Rojo-Martinez et al

Ziegler et al (4)

Poli et al (2)

Jorfida et al (2)

CRYSTAL AF-CS (3)

Carrazco et al

Dion et al

Israel et al

Makimoto et al

TRACK-AF

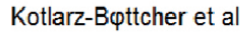

Rodrvguez-Campello et al

de Lera et al

Noone et al

Sethi et al

Kamel et al

Navarro Perez et al

SPIDER Registry

Katz et al

Pallesen et al

Asaithambi et al

CRYSTAL AF - ESUS (6)

Ching et al

REVEAL AF (5)

\section{Estimate (95\% C.I.)}

$0.167(0.072,0.261)$

$0.273(0.087,0.459)$

$0.255(0.135,0.375)$

$0.165(0.086,0.244)$

$0.337(0.244,0.429)$

$0.215(0.192,0.238)$

$0.338(0.230,0.446)$

$0.463(0.330,0.596)$

$0.299(0.238,0.359)$

$0.310(0.219,0.401)$

$0.042(0.000,0.122)$

$0.236(0.161,0.311)$

$0.226(0.158,0.294)$

$0.181(0.107,0.255)$

$0.170(0.096,0.244)$

$0.464(0.280,0.649)$

$0.423(0.347,0.499)$

$0.484(0.308,0.660)$

$0.274(0.212,0.336)$

$0.297(0.267,0.327)$

$0.270(0.127,0.413)$

$0.172(0.079,0.264)$

$0.067(0.000,0.140)$

$0.187(0.098,0.275)$

$0.281(0.198,0.363)$

$0.385(0.299,0.472)$

$0.311(0.243,0.379)$

$0.329(0.225,0.433)$

Overall $\left(I^{\wedge} 2=83 \%, P<0.001\right)$

$0.264(0.224,0.305)$
Ev/Trt

$10 / 60$

$6 / 22$

$13 / 51$

$14 / 85$

$34 / 101$

$268 / 1247$

$25 / 74$

$25 / 54$

$66 / 221$

$31 / 100$

$1 / 24$

$29 / 123$

$33 / 146$

$19 / 105$

$17 / 100$

$13 / 28$

$69 / 163$

$15 / 31$

$54 / 197$

$263 / 886$

$10 / 37$

$11 / 64$

$3 / 45$

$14 / 75$

$32 / 114$

$47 / 122$

$55 / 177$

$26 / 79$

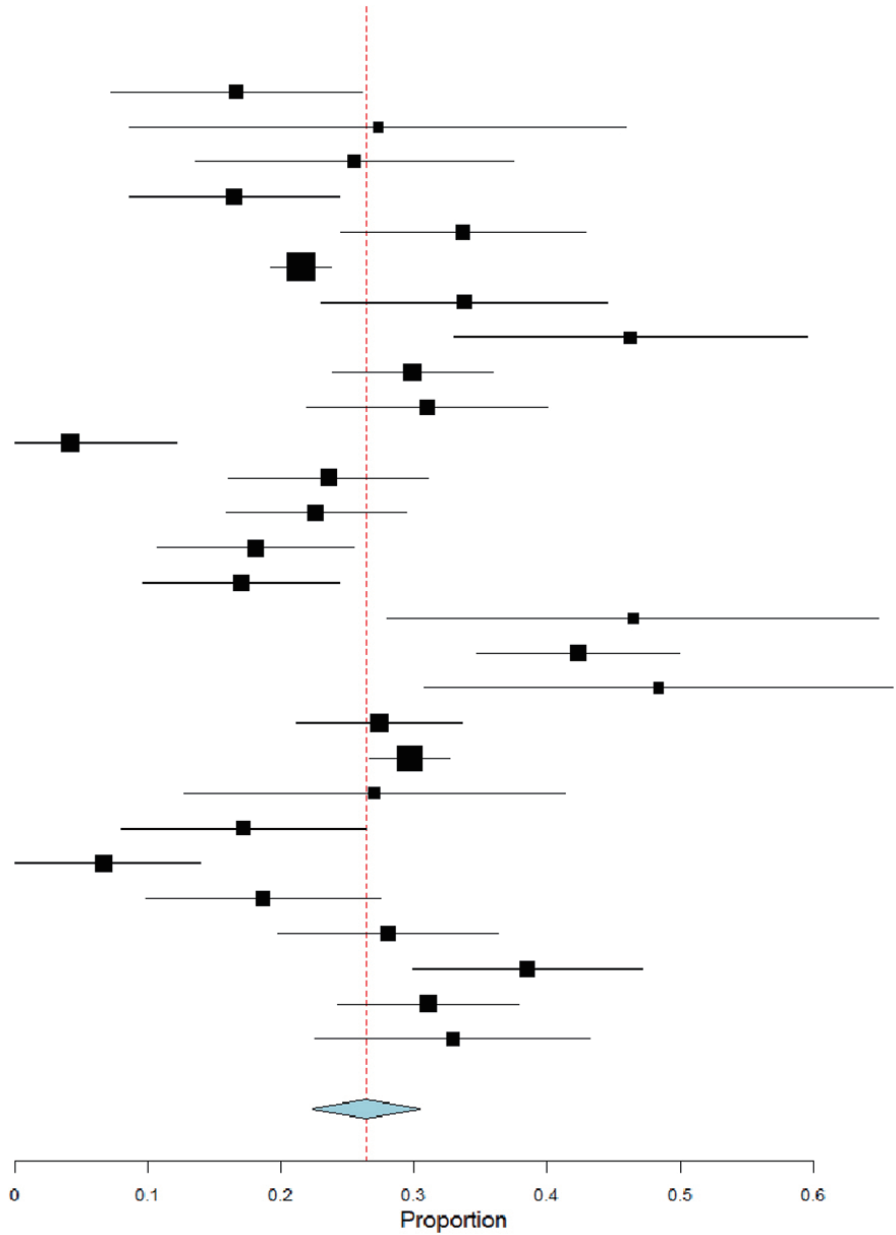

Supplementary Figure 2. Overall analysis of the cumulative rate of atrial fibrillation detection with implantable cardiac monitors. $\mathrm{Cl}$, confidence interval; EV/Trt, events/treated.

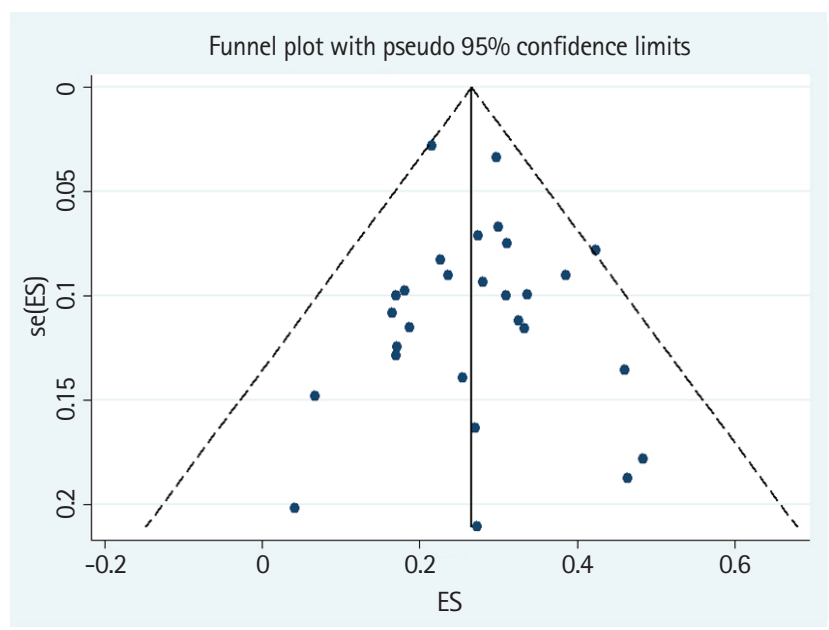

Supplementary Figure 3. Funnel plot of publication bias assessment. SE, standard error; ES, effect estimate. 

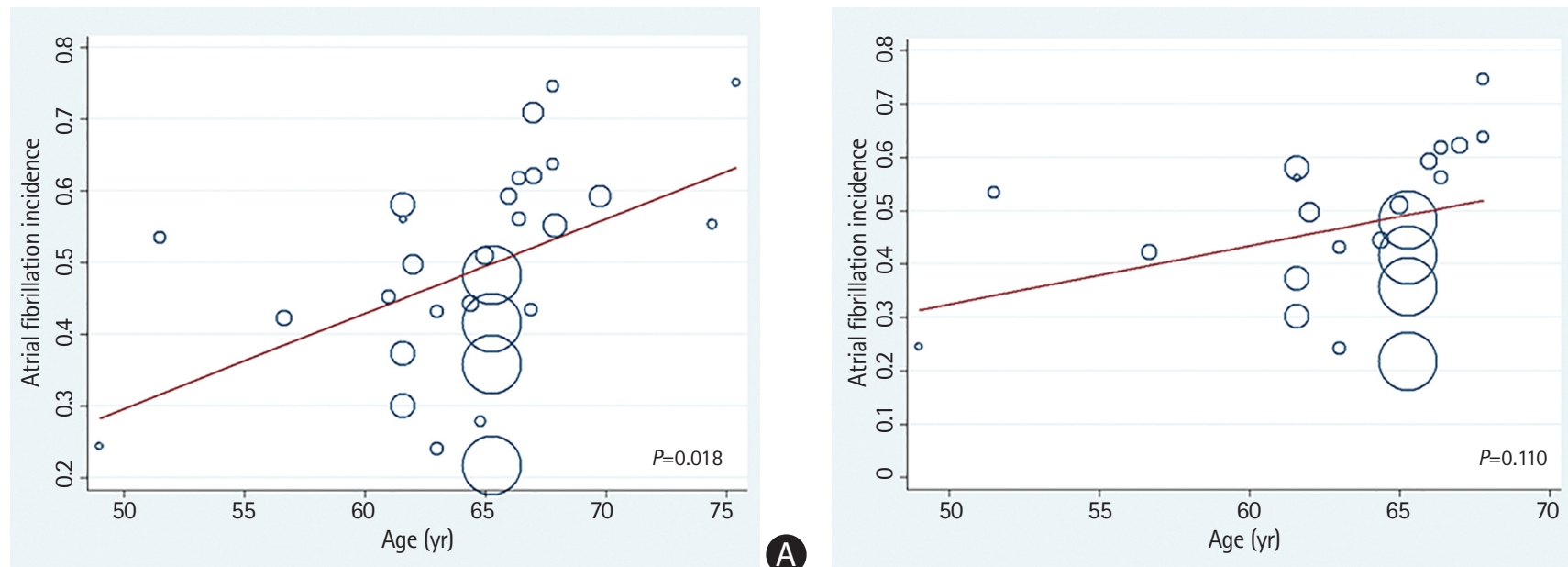

Supplementary Figure 4. Meta-regression analysis of the association of mean patient age with the rate of atrial fibrillation detection with implantable cardiac monitors reported in (A) all included (abstracts and full publications) studies and (B) fully published studies. Atrial fibrillation incidence was calculated using the double arcsine Freeman-Tukey transformation.
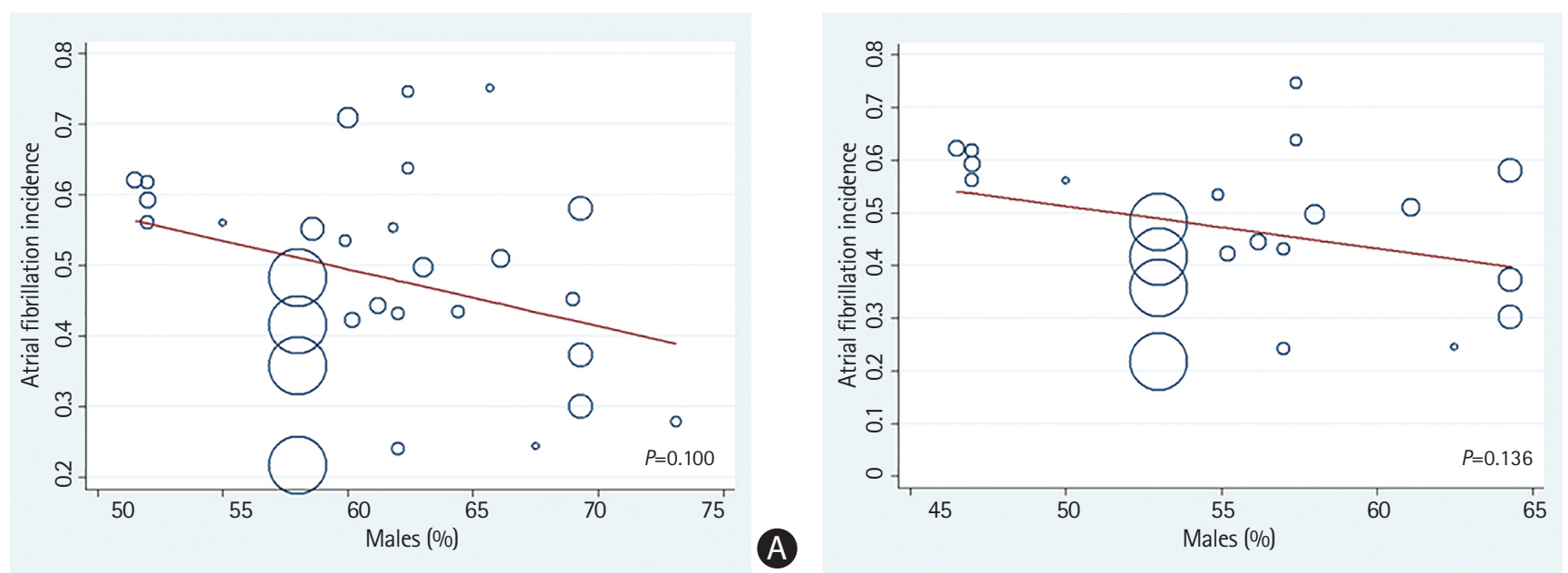

Supplementary Figure 5. Meta-regression analysis of the association of sex with the rate of atrial fibrillation detection with implantable cardiac monitors reported in (A) all included (abstracts and full publications) studies and (B) fully published studies. Atrial fibrillation incidence was calculated using the double arcsine Freeman-Tukey transformation. 

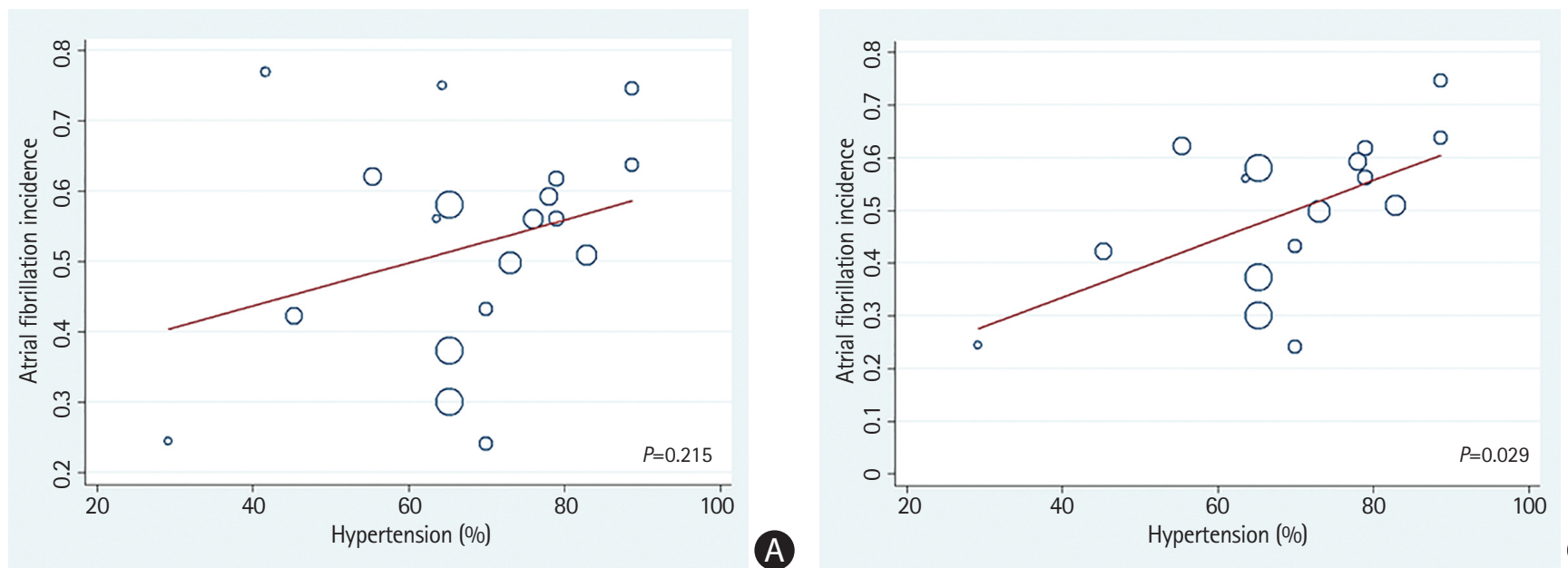

Supplementary Figure 6. Meta-regression analysis of the association of hypertension with the rate of atrial fibrillation detection with implantable cardiac monitors reported in (A) all included (abstracts and full publications) studies and (B) fully published studies. Atrial fibrillation incidence was calculated using the double arcsine Freeman-Tukey transformation.
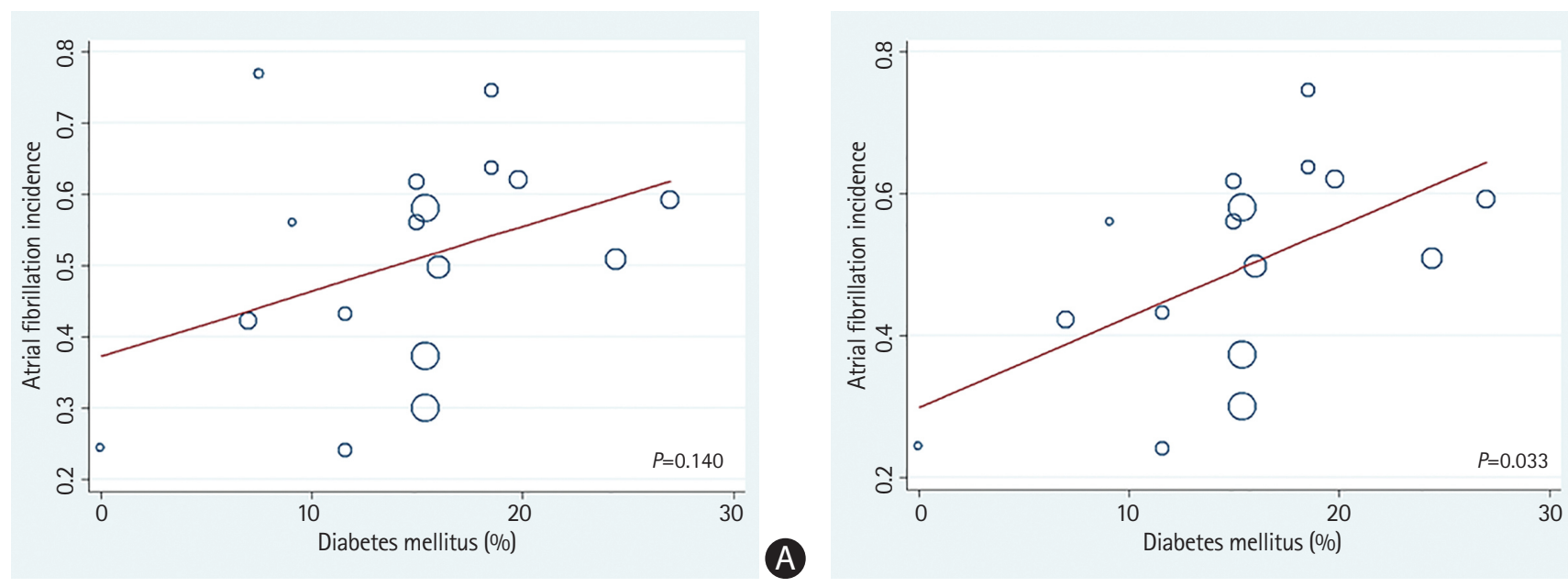

Supplementary Figure 7. Meta-regression analysis of the association of diabetes mellitus with the rate of atrial fibrillation detection with implantable cardiac monitors reported in (A) all included (abstracts and full publications) studies and (B) fully published studies. Atrial fibrillation incidence was calculated using the double arcsine Freeman-Tukey transformation. 

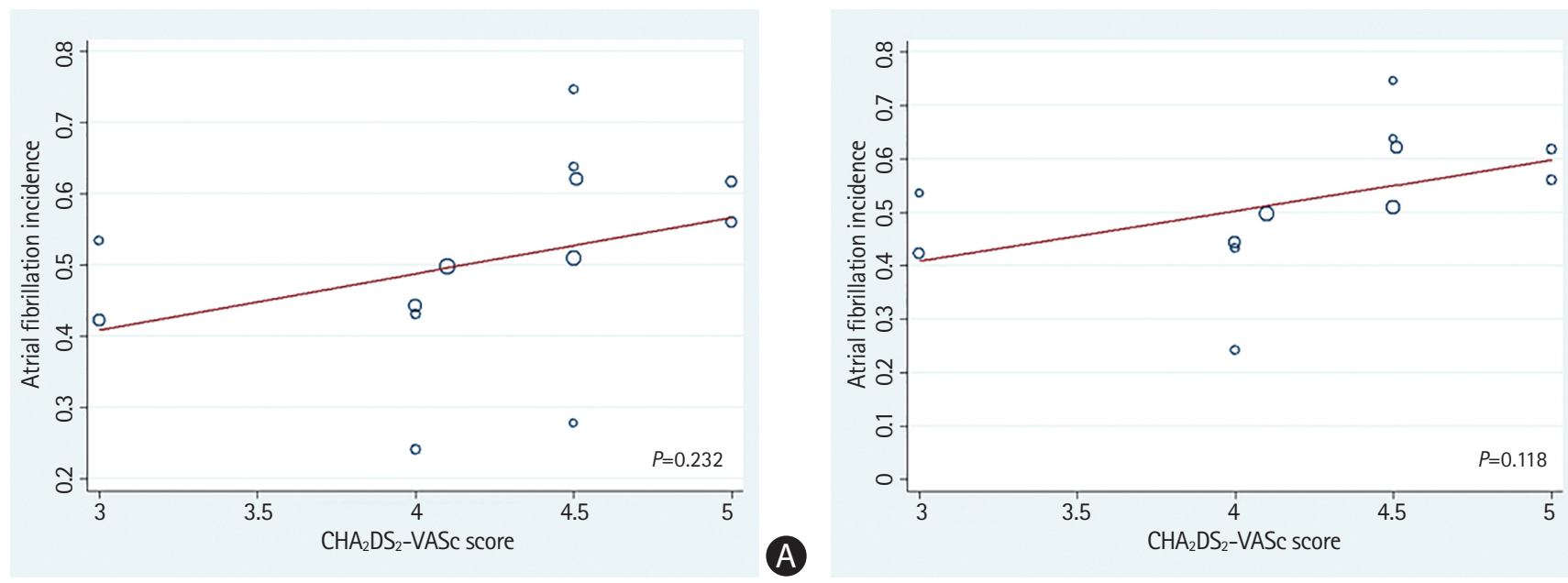

Supplementary Figure 8. Meta-regression analysis of the association of mean patient $\mathrm{CHA}_{2} \mathrm{DS}_{2} \mathrm{VASc}$ score with the rate of atrial fibrillation detection with implantable cardiac monitors reported in (A) all included (abstracts and full publications) studies and (B) fully published studies. Atrial fibrillation incidence was calculated using the double arcsine Freeman-Tukey transformation.
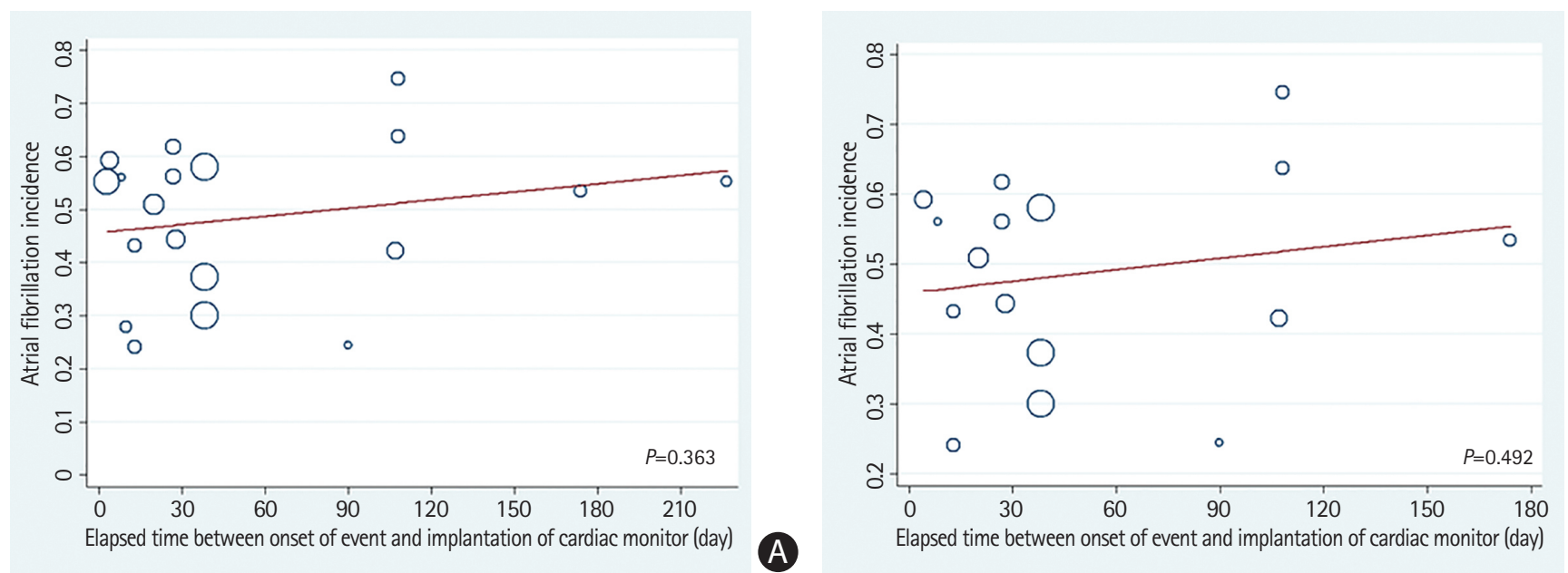

Supplementary Figure 9. Meta-regression analysis on the association of mean elapsed time from ischemic stroke or transient ischemic attack onset to cardiac monitor implantation, with the rate of atrial fibrillation detection with implantable cardiac monitors reported in (A) all included (abstracts and full publications) studies and (B) fully published studies. Atrial fibrillation incidence was calculated using the double arcsine Freeman-Tukey transformation. 


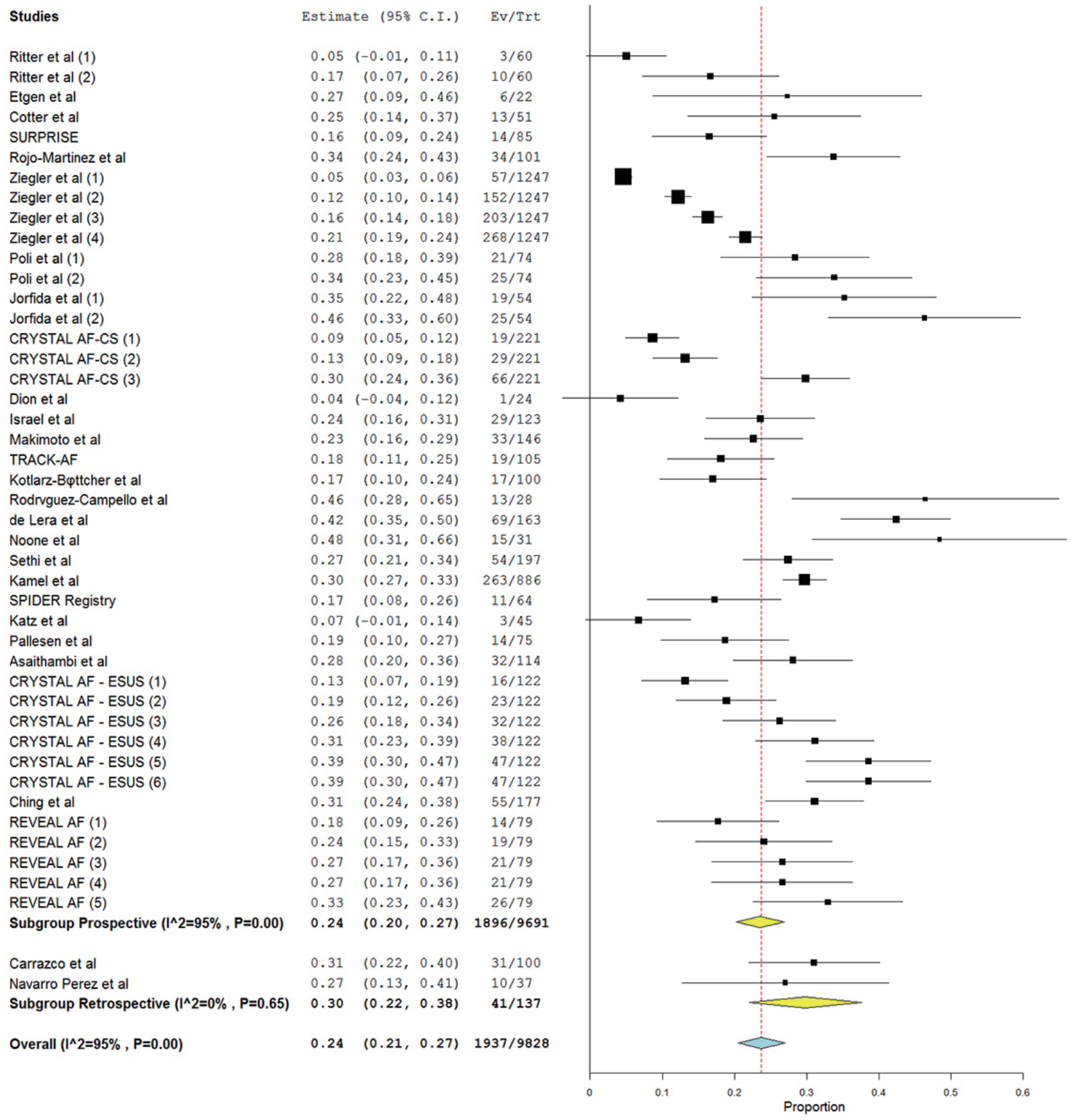

Supplementary Figure 10. Subgroup analysis of the rate of atrial fibrillation detection with implantable cardiac monitors, stratified by study type (prospective or retrospective cohort), in all included studies. $\mathrm{Cl}$, confidence interval; EV/Trt, events/treated. 


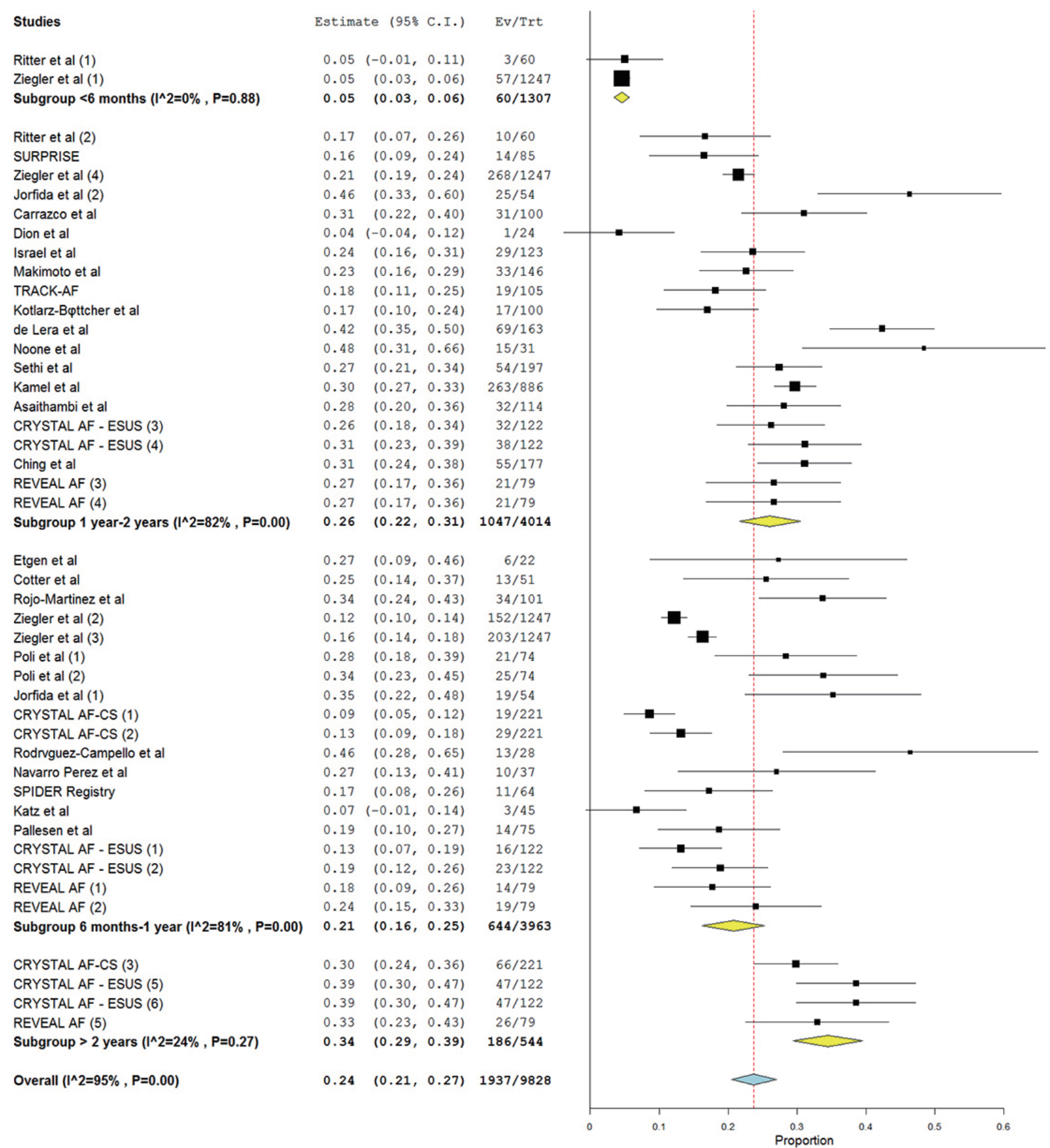

Supplementary Figure 11. Subgroup analysis of the rate of atrial fibrillation detection with implantable cardiac monitors, stratified by monitoring duration $(<6, \geq 6$ and $\leq 12,>12$ and $\leq 24$, and $>24$ months), in all included studies. $\mathrm{Cl}$, confidence interval; EV/Trt, events/treated. 


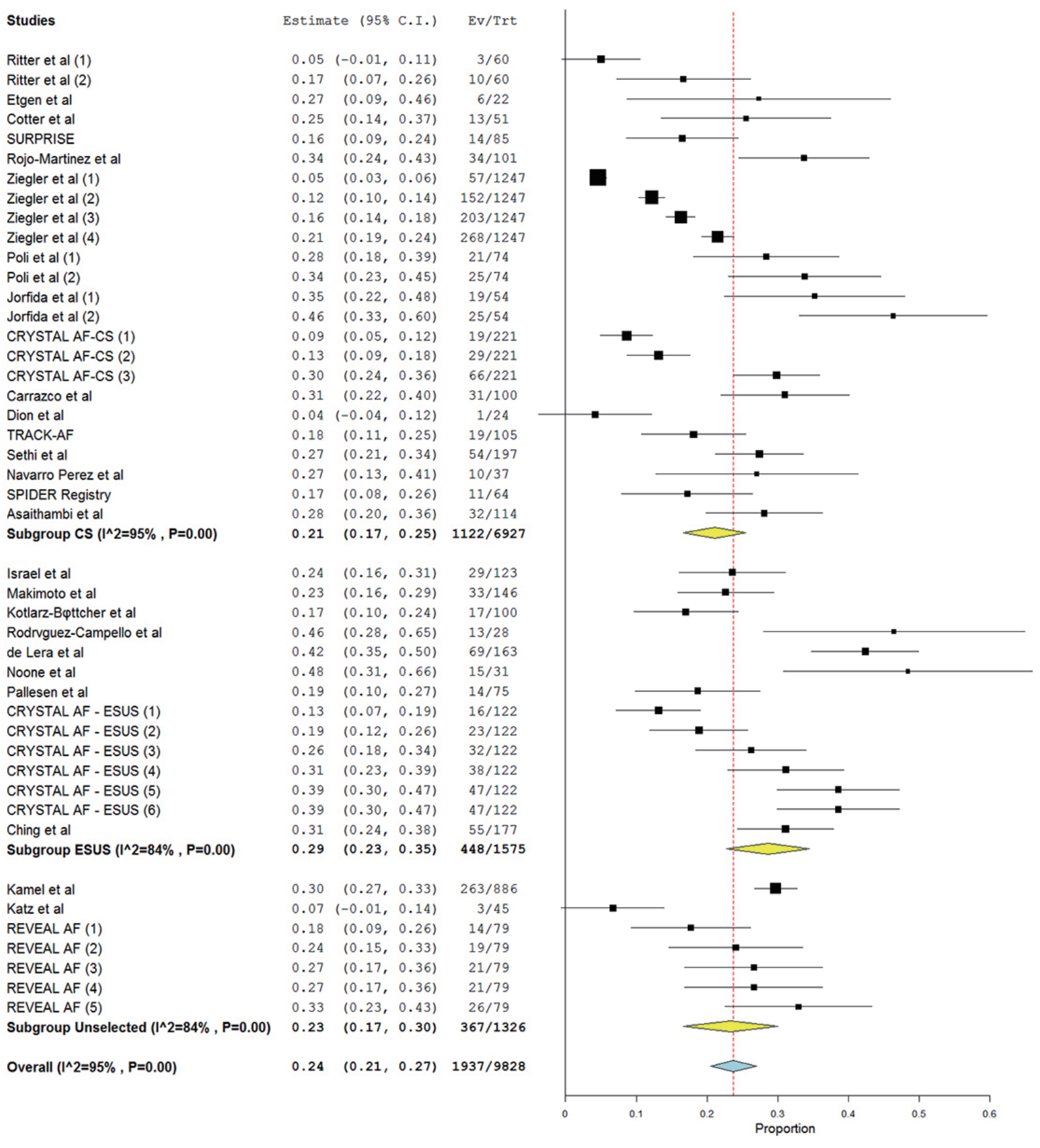

Supplementary Figure 12. Subgroup analysis of the rate of atrial fibrillation detection with implantable cardiac monitors, stratified by ischemic stroke subtype (cryptogenic stroke [CS], embolic stroke of undetermined source [ESUS], unselected ischemic stroke/transient ischemic attack), in all included studies. Cl, confidence interval; EV/Trt, events/treated. 


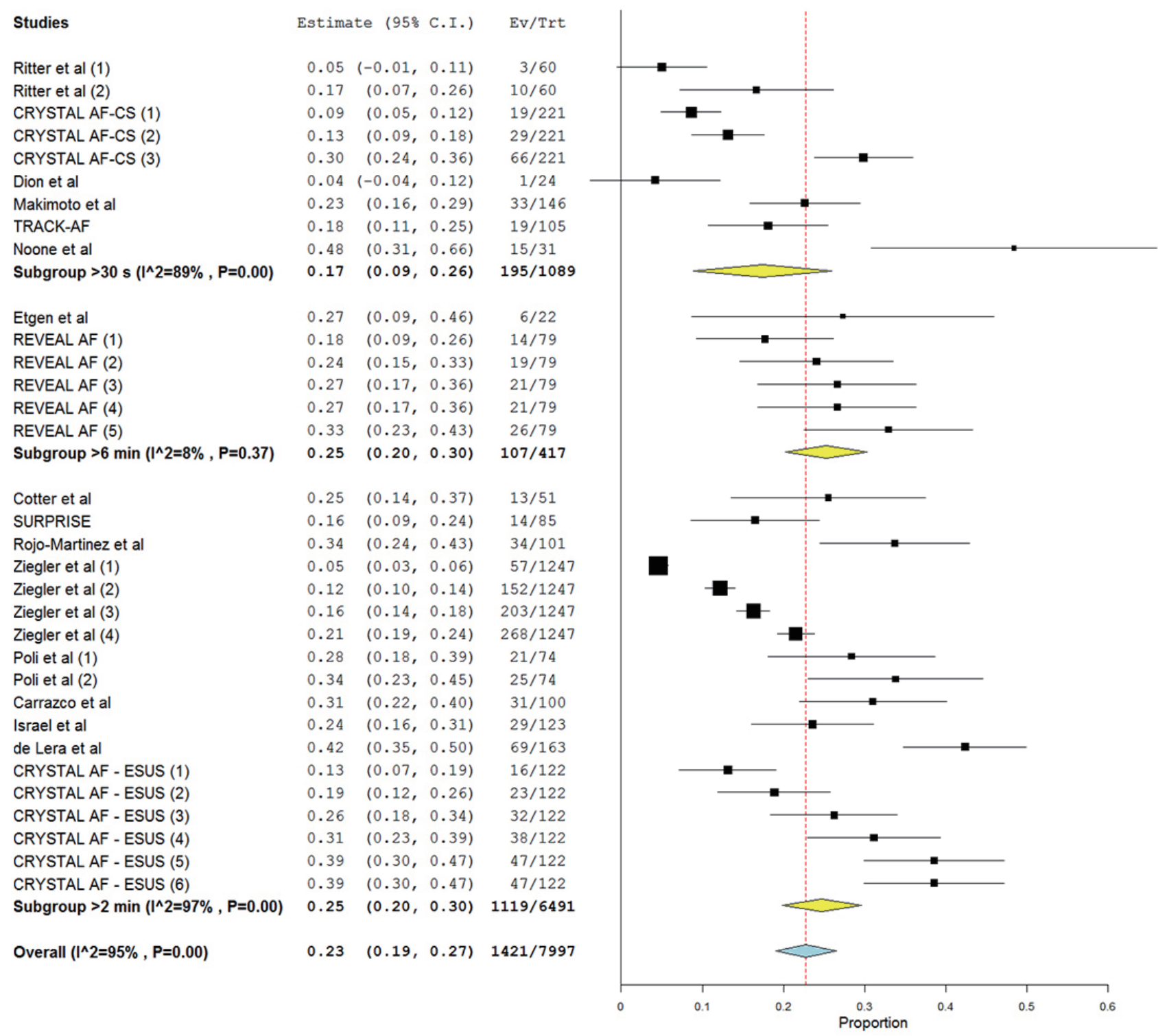

Supplementary Figure 13. Subgroup analysis of the rate of atrial fibrillation detection with implantable cardiac monitors, stratified by the time threshold used for atrial fibrillation diagnosis (30 seconds, 2 minutes, 6 minutes), in all included studies. Cl, confidence interval; EV/Trt, events/treated. 


\begin{tabular}{|c|c|c|c|c|}
\hline Studies & Estimat & ate $195 \%$ & (C.I.) & Ev/Trt \\
\hline Ritter et al (1) & 0.05 & $(-0.01$, & $0.11)$ & $3 / 60$ \\
\hline Ritter et al (2) & 0.17 & 10.07, & $0.26)$ & $10 / 60$ \\
\hline Etgen et al & 0.27 & (0.09, & $0.46)$ & $6 / 22$ \\
\hline Poli et al (1) & 0.28 & $(0.18$, & $0.39)$ & $21 / 74$ \\
\hline Poli et al (2) & 0.34 & $(0.23$, & $0.45)$ & $25 / 74$ \\
\hline Carrazco et al & 0.31 & $(0.22$, & $0.40)$ & $31 / 100$ \\
\hline Israel et al & 0.24 & $(0.16$, & $0.31)$ & $29 / 123$ \\
\hline TRACK-AF & 0.18 & $(0.11$, & $0.25)$ & $19 / 105$ \\
\hline Rodrvguez-Campello et al & 0.46 & $(0.28$, & $0.65)$ & $13 / 28$ \\
\hline Sethi et al & 0.27 & $(0.21$, & $0.34)$ & $54 / 197$ \\
\hline Katz et al & 0.07 & $(-0.01$, & $0.14)$ & $3 / 45$ \\
\hline Subgroup $<1$ month $\left(\left.\right|^{\wedge} 2=86 \%, P=0.00\right)$ & 0.23 & 10.16 & $0.30)$ & $214 / 888$ \\
\hline Cotter et al & 0.25 & $(0.14$, & $0.37)$ & $13 / 51$ \\
\hline SURPRISE & 0.16 & $(0.09$, & $0.24)$ & $14 / 85$ \\
\hline Rojo-Martinez et al & 0.34 & $(0.24$, & $0.43)$ & $34 / 101$ \\
\hline Jorfida et al (1) & 0.35 & $(0.22$, & $0.48)$ & $19 / 54$ \\
\hline Jorfida et al (2) & 0.46 & $(0.33$, & $0.60)$ & $25 / 54$ \\
\hline CRYSTAL AF-CS (1) & 0.09 & (0.05, & $0.12)$ & $19 / 221$ \\
\hline CRYSTAL AF-CS (2) & 0.13 & 10.09, & $0.18)$ & $29 / 221$ \\
\hline CRYSTAL AF-CS (3) & 0.30 & (0.24, & $0.36)$ & $66 / 221$ \\
\hline Dion et al & 0.04 & $(-0.04$, & $0.12)$ & $1 / 24$ \\
\hline Navarro Perez et al & 0.27 & 10.13 & $0.41)$ & $10 / 37$ \\
\hline Subgroup $>1$ month $\left(\left.\right|^{\wedge} 2=90 \%, P=0.00\right)$ & 0.23 & $(0.15$, & $0.31)$ & $230 / 1069$ \\
\hline Overall $\left(I^{\wedge} 2=88 \%, P=0.00\right)$ & 0.23 & $(0.18$, & $0.28)$ & $444 / 1957$ \\
\hline
\end{tabular}

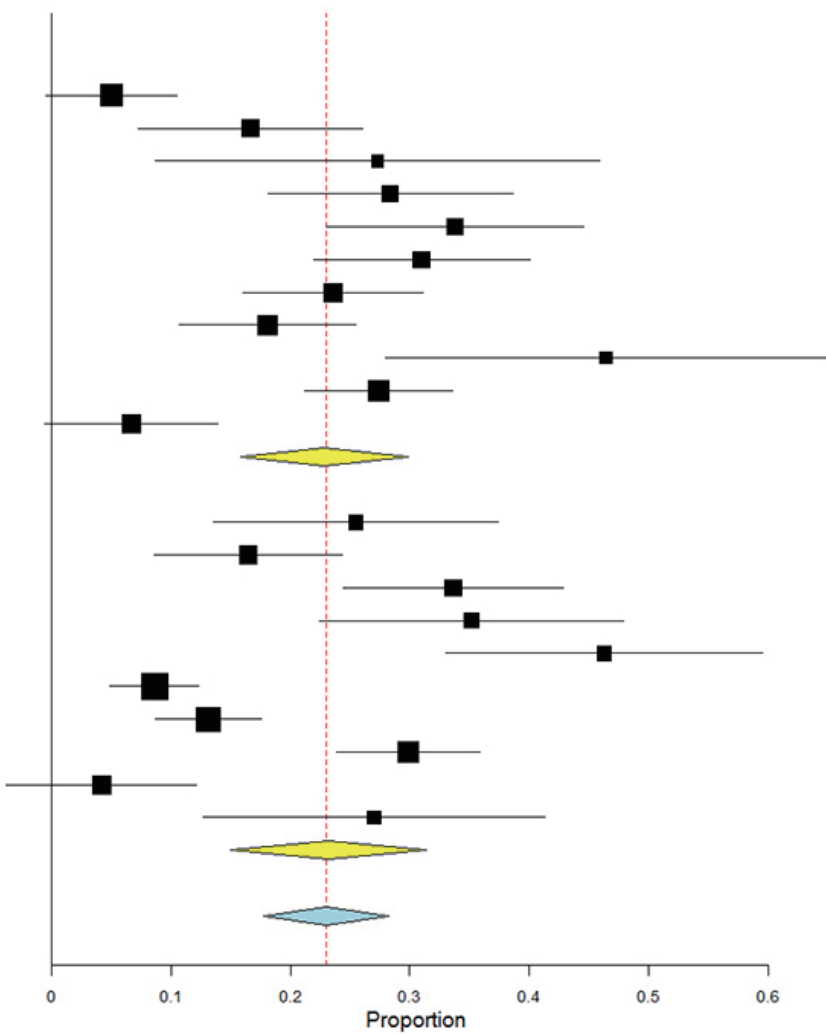

Supplementary Figure 14. Subgroup analysis of the rate of atrial fibrillation detection with implantable cardiac monitors, stratified by the elapsed time between ischemic stroke/transient ischemic attack onset and implantation of cardiac monitor ( $\leq 1$ and $>1$ month), in all included studies. $\mathrm{Cl}$, confidence interval; $\mathrm{EV} /$ Trt, events/treated.

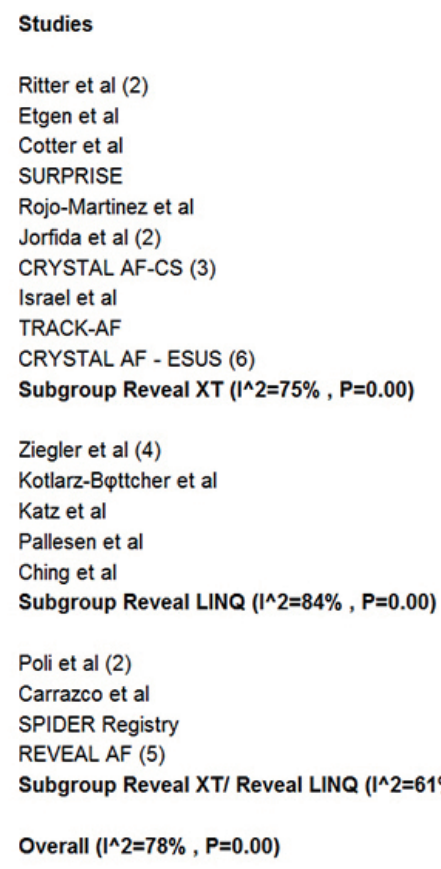
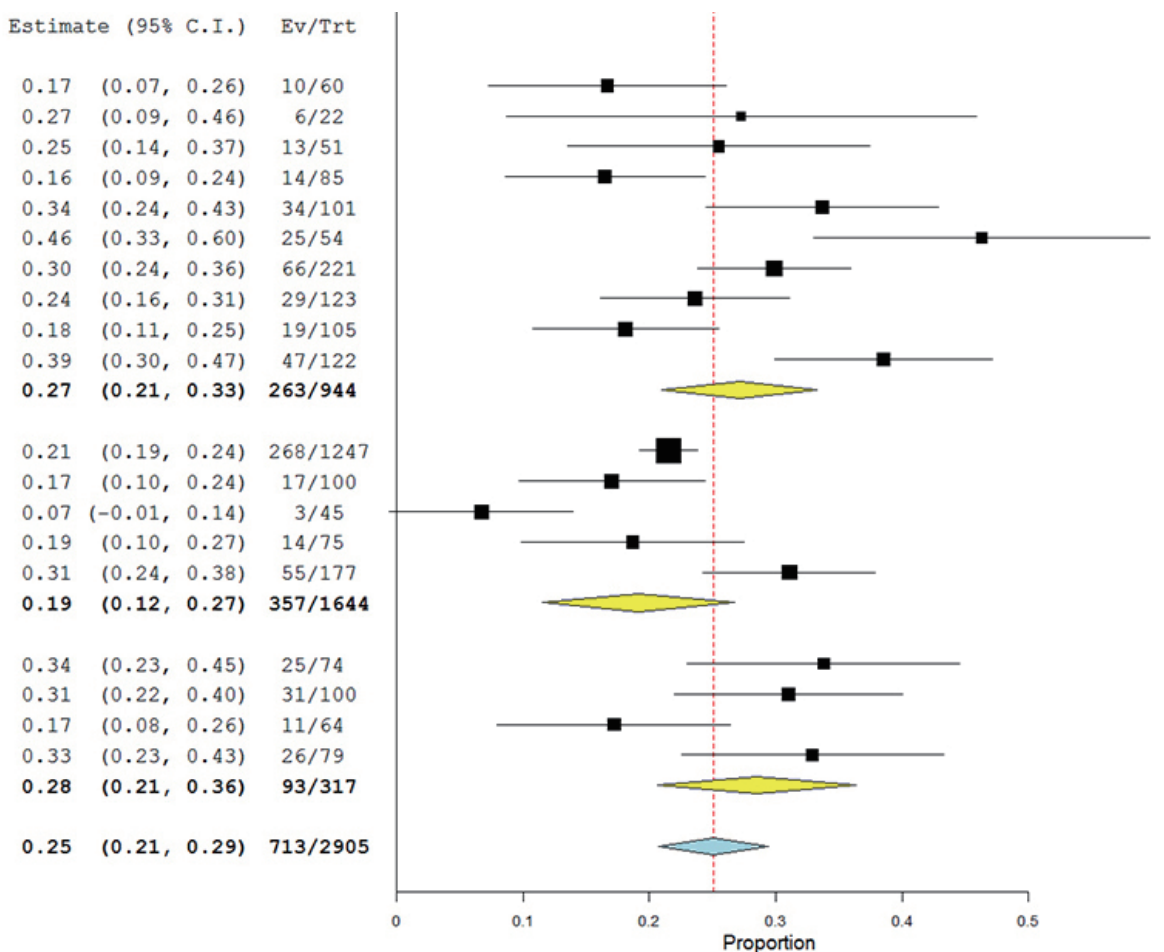

Supplementary Figure 15. Subgroup analysis of the rate of atrial fibrillation detection with implantable cardiac monitors, stratified by the type of device used, in all included studies. $\mathrm{Cl}$, confidence interval; EV/Trt, events/treated. 


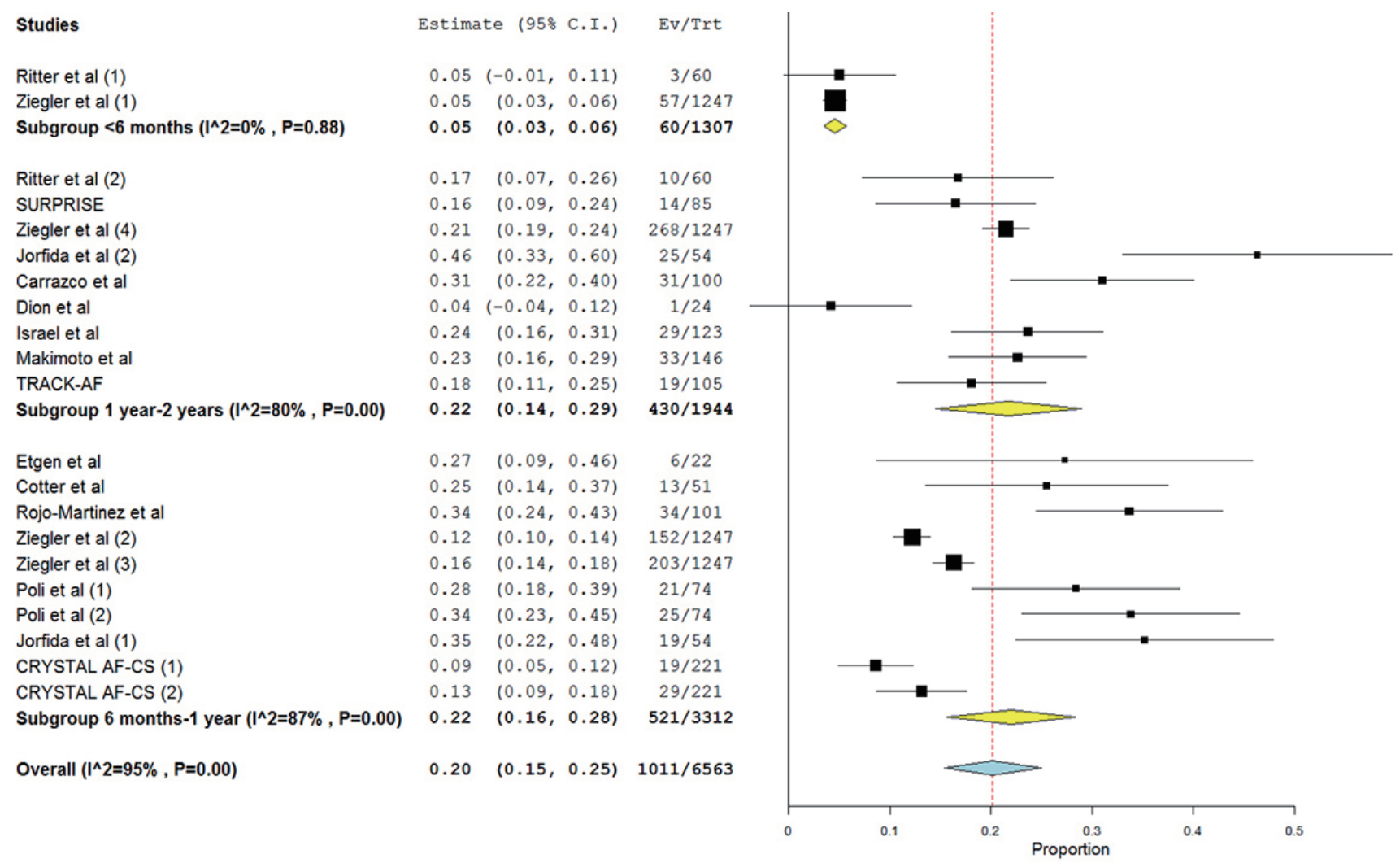

Supplementary Figure 16. Subgroup analysis of the rate of atrial fibrillation detection with implantable cardiac monitors, stratified by monitoring duration $(<6, \geq 6$ and $\leq 12,>12$ and $\leq 24$ months), in fully published studies. $\mathrm{Cl}$, confidence interval; EV/Trt, events/treated. 


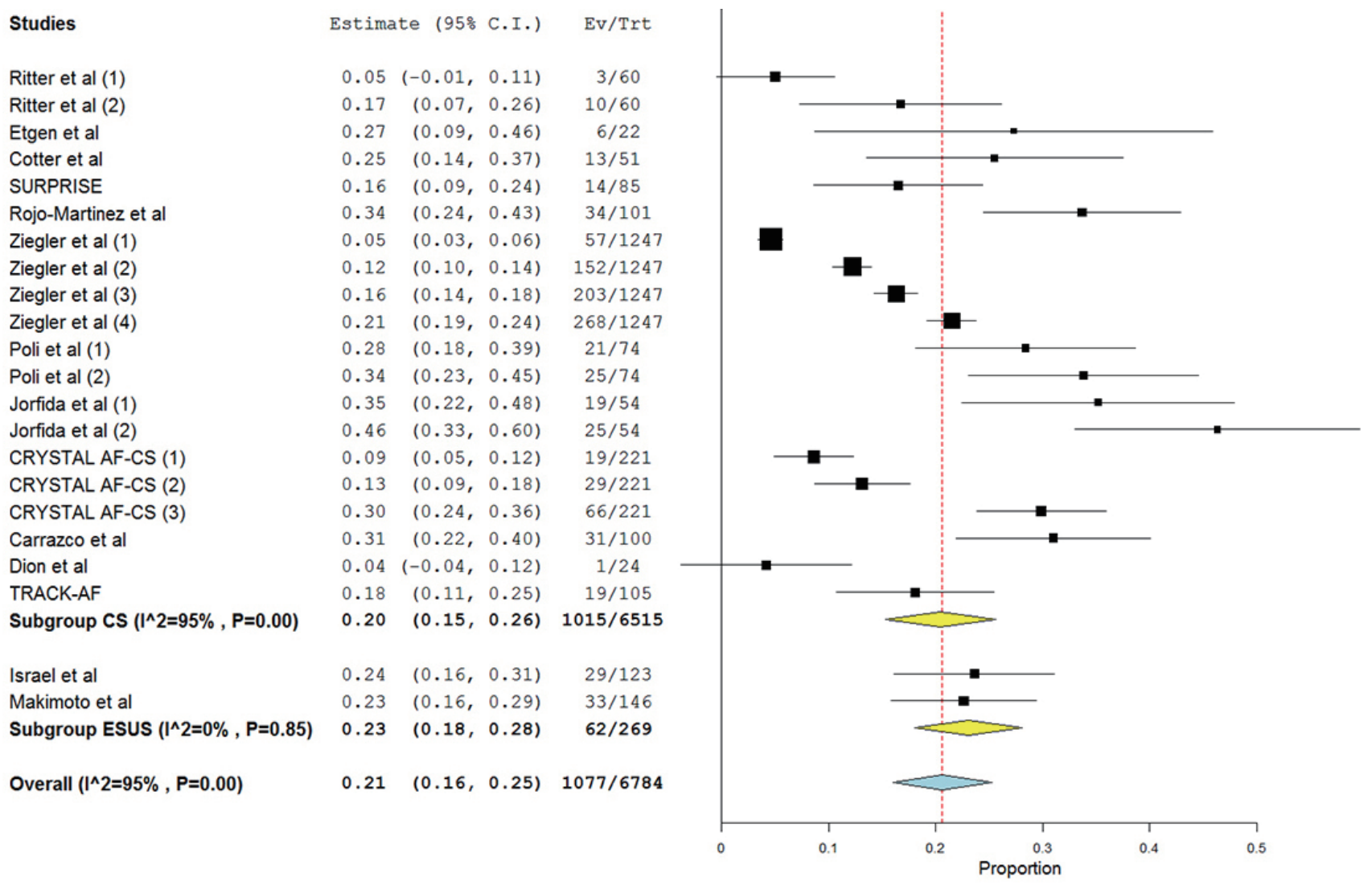

Supplementary Figure 17. Subgroup analysis of the rate of atrial fibrillation detection with implantable cardiac monitors, stratified by ischemic stroke subtype (cryptogenic stroke [CS], embolic stroke of undetermined source [ESUS]), in fully published studies. Cl, confidence interval; EV/Trt, events/treated. 


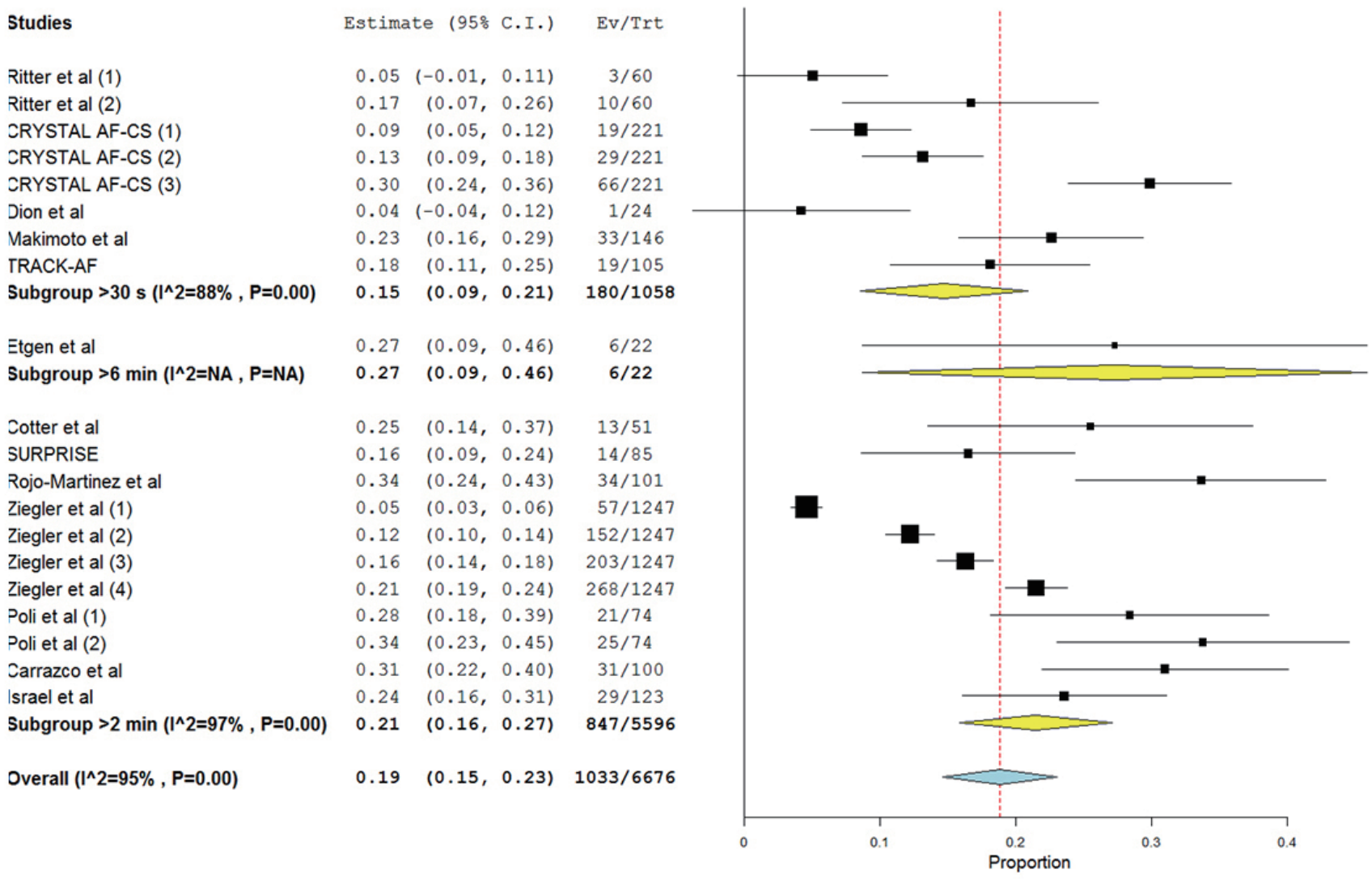

Supplementary Figure 18. Subgroup analysis of the rate of atrial fibrillation detection with implantable cardiac monitors, stratified by the time threshold used for atrial fibrillation diagnosis (30 seconds and 2 minutes) in fully published studies. $\mathrm{Cl}$, confidence interval; EV/Trt, events/treated; NA, not available.

\begin{tabular}{|c|c|c|c|c|}
\hline Studies & Estima & ate $195 \%$ & C.I.) & Ev/Trt \\
\hline Ritter et al (1) & 0.05 & $(-0.01$ & $0.11)$ & $3 / 60$ \\
\hline Ritter et al (2) & 0.17 & $(0.07$ & $0.26)$ & $10 / 60$ \\
\hline Etgen et al & 0.27 & $(0.09$, & $0.46)$ & $6 / 22$ \\
\hline Poli et al (1) & 0.28 & $(0.18$, & $0.39)$ & $21 / 74$ \\
\hline Poli et al (2) & 0.34 & $(0.23$, & $0.45)$ & $25 / 74$ \\
\hline Carrazco et al & 0.31 & $(0.22$, & $0.40)$ & $31 / 100$ \\
\hline |srael et al & 0.24 & $(0.16$, & $0.31)$ & $29 / 123$ \\
\hline TRACK-AF & 0.18 & $(0.11$, & $0.25)$ & $19 / 105$ \\
\hline Subgroup $<1$ month $\left(\left.\right|^{\wedge} 2=84 \%, P=0.00\right)$ & 0.22 & (0.15, & $0.29)$ & $144 / 618$ \\
\hline Cotter et al & 0.25 & $(0.14$, & $0.37)$ & $13 / 51$ \\
\hline SURPRISE & 0.16 & (0.09, & $0.24)$ & $14 / 85$ \\
\hline Rojo-Martinez et al & 0.34 & $(0.24 ，$ & $0.43)$ & $34 / 101$ \\
\hline Jorfida et al (1) & 0.35 & $(0.22$, & $0.48)$ & $19 / 54$ \\
\hline Jorfida et al (2) & 0.46 & (0.33, & $0.60)$ & $25 / 54$ \\
\hline CRYSTAL AF-CS (1) & 0.09 & $(0.05$, & $0.12)$ & $19 / 221$ \\
\hline CRYSTAL AF-CS (2) & 0.13 & (0.09, & $0.18)$ & $29 / 221$ \\
\hline CRYSTAL AF-CS (3) & 0.30 & $(0.24$, & $0.36)$ & $66 / 221$ \\
\hline Jion et al & 0.04 & $(-0.04$, & $0.12)$ & $1 / 24$ \\
\hline Subgroup $>1$ month $\left(\left.\right|^{\wedge} 2=91 \%, P=0.00\right)$ & 0.23 & $(0.14$ & $0.32)$ & $220 / 1032$ \\
\hline Overall $\left(l^{\wedge} 2=88 \%, P=0.00\right)$ & 0.23 & $(0.17$, & $0.28)$ & $364 / 1650$ \\
\hline
\end{tabular}

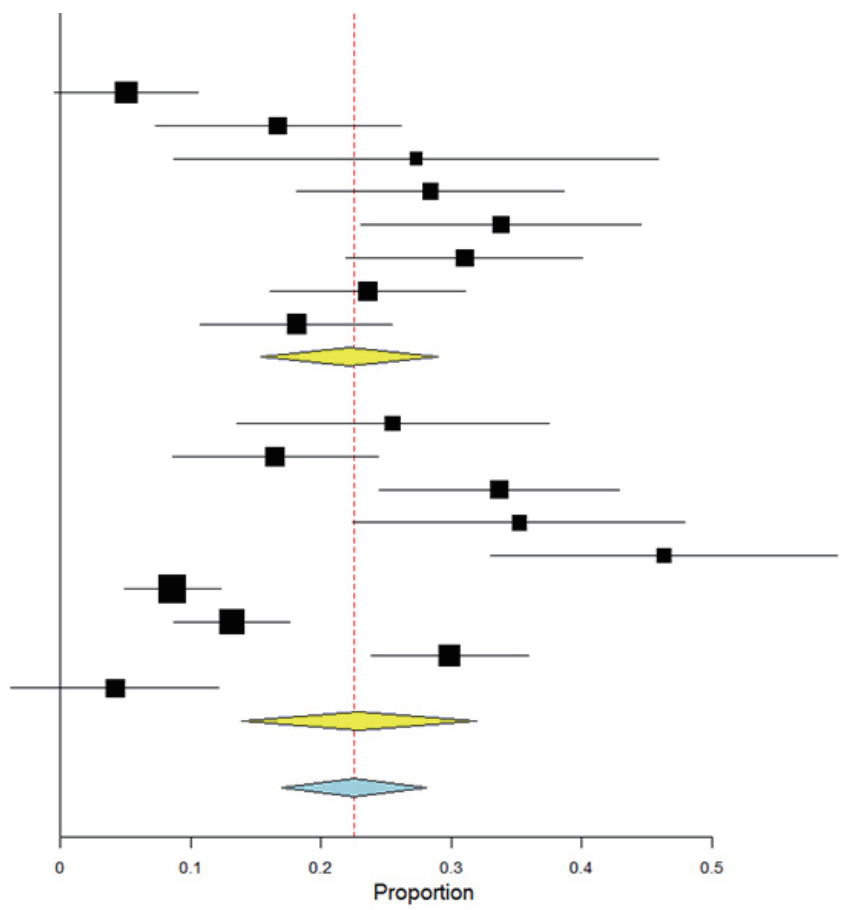

Supplementary Figure 19. Subgroup analysis of the rate of atrial fibrillation detection with implantable cardiac monitors, stratified by the elapsed time between ischemic stroke/transient ischemic attack onset and implantation of cardiac monitor ( $\leq 1$ and $>1$ month), in fully published studies. Cl, confidence interval; EV/Trt, events/treated. 


Studies
Ritter et al (2)
Etgen et al
Cotter et al
SURPRISE
Rojo-Martinez et al
Jorfida et al (2)
CRYSTAL AF-CS (3)
Israel et al
TRACK-AF
Subgroup Reveal XT (I^2=70\%, P=0.00)
Poli et al (2)
Carrazco et al
Subgroup Reveal XT/ Reveal LINQ (I^2=0\%, P=0.70)
Overall (|^2=67\% , P=0.00)
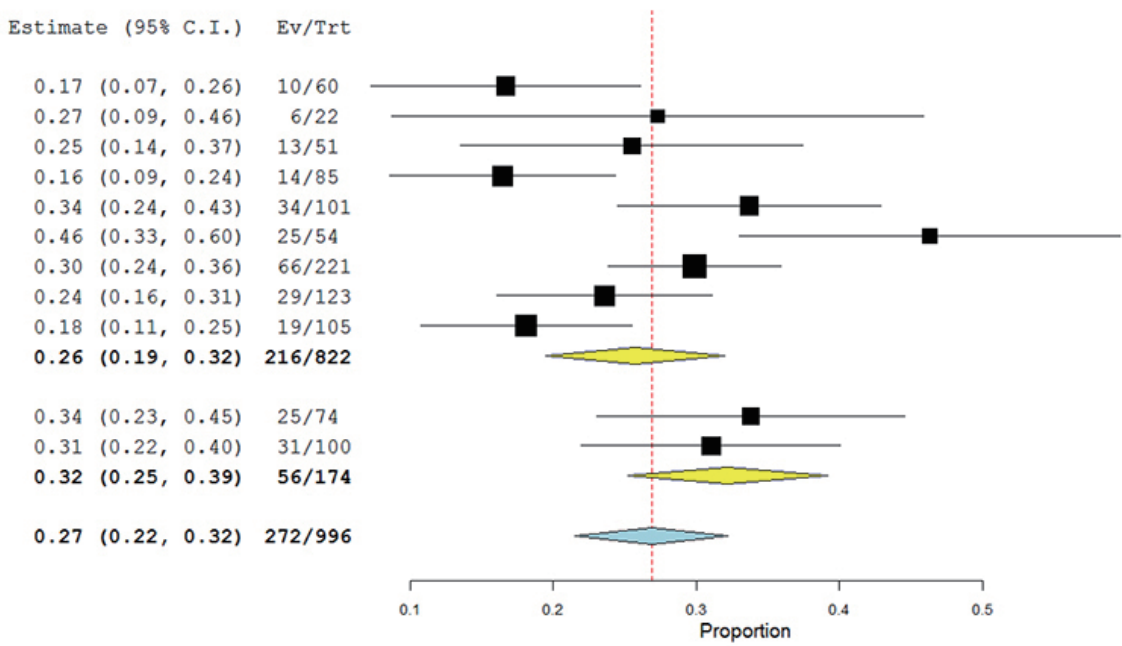

Supplementary Figure 20. Subgroup analysis of the rate of atrial fibrillation detection with implantable cardiac monitors, stratified by the type of device used, in all included studies. $\mathrm{Cl}$, confidence interval; EV/Trt, events/treated.

Studies

Etgen et al
Cotter et al
SURPRISE
Poli et al (1)
Jorfida et al (1)
CRYSTAL AF-CS (2)
Dion et al

Overall $\left(\left.\right|^{\wedge} 2=29 \%, P=0.21\right)$
Estimate (95\% C.I.) Ev/Trt
$0.67(0.29,1.00) \quad 4 / 6$
$0.92(0.78,1.00) 12 / 13$
$0.97(0.88,1.00) \quad 14 / 14$
$0.90(0.78,1.00) \quad 19 / 21$
$0.74(0.54,0.93) \quad 14 / 19$
$0.79(0.65,0.94) \quad 23 / 29$
$0.75(0.15,1.00) \quad 1 / 1$

$0.87(0.78,0.96) 87 / 103$

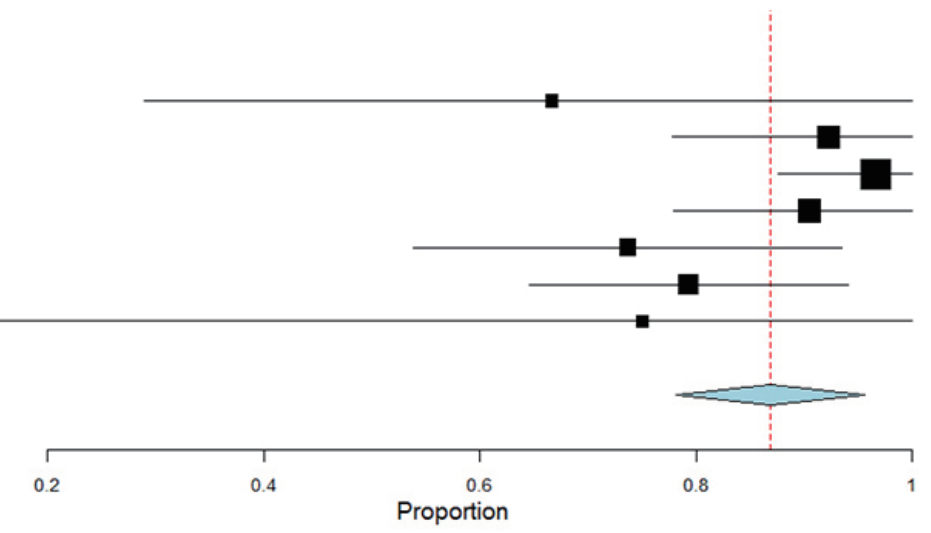

Supplementary Figure 21. Pooled analysis of the proportion patients with episodes of asymptomatic atrial fibrillation, among patients with episodes of atrial fibrillation (both asymptomatic and symptomatic) detected with implantable cardiac monitoring. $\mathrm{Cl}$, confidence interval; EV/Trt, events/treated. 


\section{Supplementary References}

1. de Lera M, Bulnes LR, Cortijo E, Bombín S, Calleja Al, García-

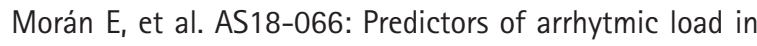
patients with cryptogenic stroke and covert atrial fibrillation detected by implantable loop recorders. Eur Stroke J 2017;2(1 Suppl):115.

2. Favilla CG, Ingala E, Jara J, Fessler E, Cucchiara B, Messé SR, et al. Predictors of finding occult atrial fibrillation after cryptogenic stroke. Stroke 2015;46:1210-1215.

3. Friberg $L$, Rosenqvist $M$, Lindgren A, Terént A, Norrving $B$, Asplund $\mathrm{K}$. High prevalence of atrial fibrillation among patients with ischemic stroke. Stroke 2014;45:2599-2605.

4. Giralt-Steinhauer E, Cuadrado-Godia E, Soriano-Tárraga C, Ois Á, Jiménez-Conde J, Rodríguez-Campello $A$, et al. Newonset paroxysmal atrial fibrillation diagnosis in ischemic stroke patients. Eur Neurol 2015;74:211-217.

5. Kitsiou A, Kalyani M, Ekosso Ejangue L, Hagemeister C, Manegold J, Israel C, et al. ESOC-0735: Atrial fibrillation detection in patients with an implantable loop recorder after acute embolic stroke of unknown source (ESUS). Int J Stroke 2015;10(2 Suppl):273.

6. Kitsiou A, Kalyani M, Ekosso Ejangue L, Hagemeister C, Manegold J, Israel C, et al. Abstract TP216: Atrial fibrillation detection in patients with an implantable loop recorder after acute embolic stroke of unknown source (ESUS). Stroke 2016;47(Suppl 1):ATP216.

7. Pedersen KB, Chemnitz $A$, Madsen $C$, Sandgaard NCF, Bak $S$, Brandes $A$. Low incidence of atrial fibrillation in patients with transient ischemic attack. Cerebrovasc Dis Extra 2016;6: 140-149.

8. Prakapenia A, Pallesen LP, Mayer J, Barlinn J, Barlinn K, Siepmann T, et al. AS18-059: Detection rate of insertable cardiac monitors is not influenced by embolic pattern in neuroradiological imaging. Eur Stroke J 2017;2(1 Suppl):113.

9. Perera KS, Vanassche T, Bosch J, Swaminathan B, Mundl $H_{1}$ Giruparajah $M$, et al. Global survey of the frequency of atrial fibrillation-associated stroke: embolic stroke of undetermined source global registry. Stroke 2016;47:2197-2202.

10. Rem JA, Hachinski VC, Boughner DR, Barnett HJ. Value of cardiac monitoring and echocardiography in TIA and stroke patients. Stroke 1985;16:950-956.

11. Ricci $B$, Chang AD, Hemendinger M, Dakay K, Cutting S, Burton $T_{1}$ et al. A simple score that predicts paroxysmal atrial fibrillation on outpatient cardiac monitoring after embolic stroke of unknown source. J Stroke Cerebrovasc Dis 2018;27: 1692-1696.

12. Rizos T, Quilitzsch A, Busse $\mathrm{O}$, Haeusler KG, Endres M, Heus-

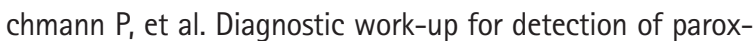
ysmal atrial fibrillation after acute ischemic stroke: crosssectional survey on German stroke units. Stroke 2015;46: 1693-1695.

13. Rodríguez-Campello A, Giralt-Steinhauer $E$, Ois A, JiménezConde J, Avellaneda-Gómez C, Serra-Martínez $M$, et al. AS21-027: Atrial fibrillation detection and stroke recurrence in patients with early insertable cardiac monitor. A casecontrol study. Eur Stroke J 2018;3(1 Suppl):459.

14. Rojo E, Sandin-Fuentes M, Calleja Al, Largaespada G, Cortijo E, Garcia-Morán E, et al. Abstract T MP57: Coexisting cerebrovascular disease and risk of occult atrial fibrillation in patients with embolic stroke of undetermined source. Stroke 2015;46(Suppl 1):ATMP57.

15. Schneider JS, Burshtein RD, Golyan D, Kahen M, Arora R, Sal-

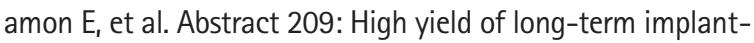
able cardiac monitoring following cryptogenic ischemic stroke. Stroke 2016;47(Suppl 1):A209.

16. Sposato $L A$, Klein $F R$, Jáuregui $A$, Ferrúa $M$, Klin $P$, Zamora $R$, et al. Newly diagnosed atrial fibrillation after acute ischemic stroke and transient ischemic attack: importance of immediate and prolonged continuous cardiac monitoring. J Stroke Cerebrovasc Dis 2012;21:210-216.

17. Stahrenberg $R$, Weber-Krüger $M$, Seegers J, Edelmann $F_{\text {, Lah- }}$ no $R$, Haase $B$, et al. Enhanced detection of paroxysmal atrial fibrillation by early and prolonged continuous holter monitoring in patients with cerebral ischemia presenting in sinus rhythm. Stroke 2010;41:2884-2888.

18. Yetim E, Topcuoglu MA, Canpolat U, Gocmen R, Oguz KK, Ozer $\mathrm{N}$, et al. Nonsustained atrial fibrillation in ischemic stroke patients and stroke-free controls from the perspective of stroke pathophysiology. J Am Heart Assoc 2016;5:e004021.

19. Asaithambi G, Monita JE, Hanson SK. Abstract WP231: Predictors for early atrial fibrillation detection among cryptogenic stroke patients with insertable cardiac monitors: a single-center experience. Stroke 2017;48(Suppl 1):AWP231.

20. Carrazco C, Golyan D, Kahen M, Black K, Libman RB, Katz JM. Prevalence and risk factors for paroxysmal atrial fibrillation and flutter detection after cryptogenic ischemic stroke. $J$ Stroke Cerebrovasc Dis 2018;27:203-209.

21. Ching Ml, Zhang C, Vaughn C, Lail N, Leahy T, Kandel A, et al. Abstract WP199: Left atrial volume index and PR interval are independent predictors of atrial fibrillation in embolic stroke patients with insertable cardiac monitor. Stroke 2018;49 (Suppl 1):AWP199.

22. Cotter PE, Martin PJ, Ring L, Warburton EA, Belham M, Pugh PJ. Incidence of atrial fibrillation detected by implantable loop recorders in unexplained stroke. Neurology 2013;80: 
1546-1550.

23. Sanna T, Diener HC, Passman RS, Di Lazzaro V, Bernstein RA, Morillo CA, et al. Cryptogenic stroke and underlying atrial fibrillation. N Engl J Med 2014;370:2478-2486.

24. Passman RS, Rymer MM, Liu S, Ziegler PD. Abstract 78: Incidence of atrial fibrillation among patients with an embolic stroke of undetermined source. Stroke 2017;48(Suppl 1):A78.

25. de Lera M, Largaespada G, Cortijo E, Sandin M, Calleja A,

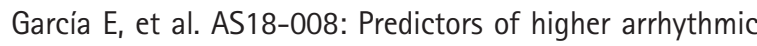
load in patients with cryptogenic stroke and covert atrial fibrillation detected by implantable loop recorders. Eur Stroke J 2016;1(1 Suppl):641.

26. Dion F, Saudeau D, Bonnaud I, Friocourt P, Bonneau A, Poret $P$, et al. Unexpected low prevalence of atrial fibrillation in cryptogenic ischemic stroke: a prospective study. J Interv Card Electrophysiol 2010;28:101-107.

27. Etgen $T$, Hochreiter $M$, Mundel $M$, Freudenberger $T$. Insertable cardiac event recorder in detection of atrial fibrillation after cryptogenic stroke: an audit report. Stroke 2013;44:20072009.

28. Israel C, Kitsiou A, Kalyani M, Deelawar S, Ejangue LE, Ro-

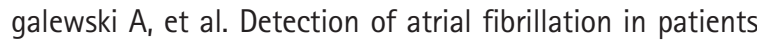
with embolic stroke of undetermined source by prolonged monitoring with implantable loop recorders. Thromb Haemost 2017;117:1962-1969.

29. Jorfida $M$, Antolini $M$, Cerrato $E$, Caprioli MG, Castagno D, Garrone $P$, et al. Cryptogenic ischemic stroke and prevalence of asymptomatic atrial fibrillation: a prospective study. J Cardiovasc Med (Hagerstown) 2016;17:863-869.

30. Kamel H, Yaghi S, Passman R, Allred J, Sarkar S, Kohler J, et al. AS21-004: Comparison of atrial fibrillation diagnosis and oral anticoagulation utilization among ischemic stroke patients with vs. without insertable cardiac monitors. Eur Stroke J 2018;3(1 Suppl):452.

31. Katz JM, Gribko M, Jadonath $R$, Arora R, Salamon E, Garlitzki $A$, et al. Abstract WMP63: Prevalence of occult paroxysmal atrial fibrillation in non-cryptogenic ischemic stroke patients. Stroke 2017;48(Suppl 1):AWMP63.

32. Kotlarz-Böttcher MJ, Busch $M$, Frenzel $M$, Hummel $A_{1}$ Schminke U, von Sarnowski B. AS21-019: Risk factors for atrial fibrillation in patients with embolic stroke of undetermined source (ESUS). Eur Stroke J 2018;3(1 Suppl):457.

33. Makimoto $H$, Kurt M, Gliem M, Lee Jl, Schmidt J, Müller $P$, et al. High incidence of atrial fibrillation after embolic stroke of undetermined source in posterior cerebral artery territory. $J$ Am Heart Assoc 2017;6:e007448.

34. Navarro Pérez MP, Pérez Lázaro C, Pelegrín Díaz J, Rodrigo Trallero G, Sánchez Val A, Garcés Antón E, et al. AS21-031:
Paroxysmal atrial fibrillation detection after cryptogenic stroke: a single center experience. Eur Stroke J 2018;3(1 Suppl):460.

35. Noone I, Meagher MK, Mc Creery C, Cassidy T. AS18-027: The role of loop recorders in embolic stroke of uncertain source (ESUS). Eur Stroke J 2016;1 (1 Suppl):16.

36. Pallesen LPM, Mayer J, Barlinn K, Barlinn J, Prakapenia A, Sieppmann T, et al. Abstract WP230: Real-life detection rate of insertable cardiac monitors in patients with ESUS. Stroke 2017;48(Suppl 1):AWP230.

37. Poli S, Diedler J, Härtig F, Götz N, Bauer A, Sachse T, et al. Insertable cardiac monitors after cryptogenic stroke: a risk factor based approach to enhance the detection rate for paroxysmal atrial fibrillation. Eur J Neurol 2016;23:375-381.

38. Elkind MS, Wachter R, Verma A, Kowey PR, Halperin JL, Gersh $B J$, et al. Abstract 189: Identifying patients at highest risk of developing atrial fibrillation and the role of remote prior stroke: insights from the REVEAL AF study. Stroke 2018;49 (Suppl 1):A189.

39. Ritter $M A$, Kochhäuser $S$, Duning $T$, Reinke F, Pott $C$, Dechering $D G$, et al. Occult atrial fibrillation in cryptogenic stroke: detection by 7-day electrocardiogram versus implantable cardiac monitors. Stroke 2013;44:1449-1452.

40. Rodríguez-Campello A, Cuadrado-Godia E, Ois A, Giralt-

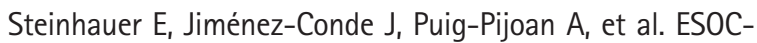
1467: Early detection of atrial fibrillation in embolic stroke of unknown origin (ESUS). Int J Stroke 2015;10:268-269.

41. Rojo-Martinez E, Sandín-Fuentes M, Calleja-Sanz Al, CortijoGarcía $E_{1}$ García-Bermejo P, Ruiz-Piñero $M$, et al. High performance of an implantable Holter monitor in the detection of concealed paroxysmal atrial fibrillation in patients with cryptogenic stroke and a suspected embolic mechanism. Rev Neurol 2013;57:251-257.

42. Sethi P, Biby S, Allred J, Seiler A, Xu J. AS18-067: Surveillance for atrial fibrillation in patients with cryptogenic stroke using an implantable loop recorder during an inpatient hospitalization in a community hospital setting. Eur Stroke $J$ 2017;2(1 Suppl):115.

43. Joseph K, Wanjiku S, Jumaa M, Richards M. Abstract W P194: Improved efficacy of ICM detection of atrial fibrillation in cryptogenic stroke patients with MRI-defined infarcts: preliminary results from the SPIDER registry. Stroke 2015;46(Suppl 1):AWP194.

44. Christensen LM, Krieger DW, Højberg S, Pedersen OD, Karlsen FM, Jacobsen MD, et al. Paroxysmal atrial fibrillation occurs often in cryptogenic ischaemic stroke. Final results from the SURPRISE study. Eur J Neurol 2014;21:884-889.

45. Reinke F, Bettin M, Ross LS, Kochhäuser S, Kleffner I, Ritter 
$M$, et al. Refinement of detecting atrial fibrillation in stroke patients: results from the TRACK-AF Study. Eur J Neurol 2018;25:631-636.

46. Ziegler PD, Rogers JD, Ferreira SW, Nichols AJ, Sarkar S, Koehler $\mathrm{J}$, et al. Real-world experience with insertable cardiac monitors to find atrial fibrillation in cryptogenic stroke.
Cerebrovasc Dis 2015;40:175-181.

47. Ziegler PD, Rogers JD, Ferreira SW, Nichols AJ, Richards M, Koehler $\mathrm{JL}$, et al. Long-term detection of atrial fibrillation with insertable cardiac monitors in a real-world cryptogenic stroke population. Int J Cardiol 2017;244:175-179. 